Supporting information for

\title{
Protected Poly(3-Sulfopropyl Methacrylate) Copolymers: Synthesis, Stability, and Orthogonal Deprotection
}

\author{
Anton H. Hofman*, Matteo Pedone, and Marleen Kamperman
}

Polymer Science, Zernike Institute for Advanced Materials, University of Groningen, Nijenborgh 4, 9747 AG Groningen, The Netherlands

*a.h.hofman@rug.nl 


\section{Experimental section}

\subsection{Materials}

Anhydrous N,N-dimethylformamide (DMF; 99.8\%), 3-sulfopropyl methacrylate potassium salt (98\%), triethylamine (99.5\%), potassium iodide $(99.0 \%)$, sodium azide $(99.5 \%)$, hydrobromic acid (48 wt\% in water), tetraethylammonium iodide (98\%), deuterated solvents, and the RAFT agent 4-cyano-4-(thiobenzoylthio)pentanoic acid (CTP) were purchased from Sigma-Aldrich. Oxalyl chloride (98.0\%), tetrabutylammonium iodide (98.0\%), and 1-ethyl-3-methylimidazolium iodide (EMIMI, 98.0\%) were acquired from TCI Europe N.V. Sodium iodide (99.5\%, anhydrous) and sodium hydroxide (97.5\%, pellets) were obtained from Acros Organics. 1,1,1,3,3,3-hexafluoro-2-propanol (HFIP, AR grade, $99.8 \%$ ) was purchased from Biosolve. The other alcohols for the monomer protection were either obtained in anhydrous form or directly used from a freshly opened analytical grade bottle. Azobisisobutyronitrile (AIBN, Sigma-Aldrich) was recrystallized twice from methanol and stored in the fridge. Thin layer chromatography (TLC) was performed on Macherey-Nagel Alugram UV254 indicator/silica-coated TLC aluminum plates. Analytical grade solvents were acquired from Macron Fine Chemicals.

\subsection{Synthesis of protected monomers}

Protected 3-sulfopropyl methacrylate monomers were synthesized according to our previously reported procedure ${ }^{1}$ that was updated with some small modifications. An example for the preparation of BSPMA is given below; other protecting groups were introduced by exchanging the alcohol in the second step.

A $100 \mathrm{ml}$ three-neck round-bottom flask that contained $10.2 \mathrm{~g} \mathrm{(41.4} \mathrm{mmol)} \mathrm{3-sulfopropyl}$ methacrylate potassium salt (K-SPMA) was subjected to three vacuum/argon cycles to remove residual traces of water. During these cycles the vacuum was maintained until the pressure reached a stable value. After putting the flask back under an argon atmosphere, K-SPMA was suspended in $30 \mathrm{ml}$ anhydrous DMF and cooled to $0{ }^{\circ} \mathrm{C}$ by using an ice bath. Next, a solution of $5.78 \mathrm{~g}(45.5 \mathrm{mmol})$ oxalyl chloride in $15 \mathrm{ml}$ dichloromethane was added dropwise via a glass pipette under an argon outflow; instantaneous gas release $\left(\mathrm{CO}_{2} / \mathrm{CO}\right)$ was observed due to formation of the Vilsmeier reagent. The reaction mixture was left to stir for approximately $1 \mathrm{~h}$ at $0{ }^{\circ} \mathrm{C}$ before continuing with the second step.

In another three-neck round-bottom flask $(250 \mathrm{ml})$ that was equipped with a dropping funnel, a solution of $3.70 \mathrm{~g}(49.9 \mathrm{mmol})$ isobutanol and $8.41 \mathrm{~g}(83.1 \mathrm{mmol})$ triethylamine was prepared in $30 \mathrm{ml}$ dichloromethane under an argon atmosphere, and cooled to $0{ }^{\circ} \mathrm{C}$. The bright yellow SPMA-Cl/ $\mathrm{KCl}$ suspension was allowed to warm up to room temperature, transferred to the dropping funnel under an argon overpressure, and added slowly over a period of about $30 \mathrm{~min}$. After completion, the resulting orange suspension was warmed up to room temperature and stirred overnight. The next morning the reaction mixture was transferred to a separation funnel, diluted with $300 \mathrm{ml} \mathrm{H}_{2} \mathrm{O}$, and extracted with three portions of diethyl ether $(200 \mathrm{ml}$ each). The combined organic fractions were washed with $200 \mathrm{ml} \mathrm{H}_{2} \mathrm{O}$ to remove traces of DMF, dried over magnesium sulfate, and concentrated in vacuo to give $9.80 \mathrm{~g}$ dark orange oil. The crude product was purified by silica gel column chromatography using hexane/ethyl acetate $(3 / 1)$ as eluent $\left(R_{f}=0.6\right)$ to afford $8.41 \mathrm{~g}$ BSPMA as a pale-yellow oil (yield: $77 \%$ ). The monomer was stored in 
the fridge until further use.

The other monomers were synthesized by following to the same procedure. PhSPMA (hexane/ethyl acetate 5/1, $R_{f}=0.4$, yield: 70\%), FSPMA (hexane/ethyl acetate 6/1, $R_{f}=0.4$, yield: $47 \%$ ), NSPMA (hexane/ethyl acetate $7 / 1, R_{f}=0.4$, yield: $75 \%$ ). ${ }^{1} \mathrm{H}-$ and ${ }^{13} \mathrm{C}-\mathrm{NMR}$ spectra are given in Figures S1-S4.

\subsection{RAFT polymerization}

An example for the polymerization of BSPMA by RAFT (PBSPMA-2) is given below. Other polymers were synthesized by adjusting the concentrations and/or monomer type as described in Table 1. Block copolymers were prepared by exchanging CTP by the corresponding macro-CTA (Table S2). For calculation of the concentrations ([CTA], [AIBN], and $[\mathrm{M}])$ the monomer density was always assumed to be $1 \mathrm{~g} \mathrm{ml}^{-1}$.

A $50 \mathrm{ml}$ two-neck round-bottom flask equipped with a stirring egg, a stopper and a rubber septum, was charged with $3.54 \mathrm{~g}$ BSPMA (13.4 mmol) and $33.2 \mathrm{mg}$ CTP (0.119 mmol). Both components were dissolved in $4.4 \mathrm{ml}$ DMF (anhydrous). Next, $1.83 \mathrm{mg}$ AIBN (0.0111 $\mathrm{mmol})$ was added via a freshly prepared stock solution in anhydrous DMF (0.9 ml; 2.03 $\mathrm{mg} \mathrm{m} \mathrm{m}^{-1}$ ). After that the clear purple solution was sparged with argon for approximately $1 \mathrm{~h}$, the flask was submerged in a thermostated oil bath at $70^{\circ} \mathrm{C}$. The polymerization was carried out for $20 \mathrm{~h}$, quenched by placing the flask in an ice bath, and the conversion was calculated from ${ }^{1} \mathrm{H}-\mathrm{NMR}$ by analyzing a few drops of the reaction mixture $\left(\mathrm{CDCl}_{3}\right.$ as solvent; $92 \%$ conversion). The viscous purple solution was diluted with $2 \mathrm{ml}$ acetone and precipitated into $180 \mathrm{ml}$ pentane/ethanol (5/1). After decantation of the supernatant, the sticky pink polymer was washed in the same beaker using ethanol, pentane/ethanol $(1 / 1)$, and finally pentane. The product was dried in vacuo for a few hours, redissolved in $9 \mathrm{ml}$ acetone, and reprecipitated/washed following the same procedure. Drying of the polymer overnight in a vacuum oven at room temperature (i.e., below the $T_{g}$ ) afforded PBSPMA as a pink foam that was crushed with a spatula to give $2.56 \mathrm{~g}$ pink powder (yield: $79 \%$ ). Protected polymers were always stored in the fridge until further use.

The other protected poly(3-sulfopropyl methacrylates) could be isolated from the reaction mixture by following the same procedure, except for PPhSPMA which was precipitated in pentane/ethanol (3/1), and PFSPMA which was diluted with and redissolved in THF instead of acetone.

\subsection{Deprotection}

A general procedure for successful cleavage (-) of each protecting group under either weak nucleophilic, strong nucleophilic, basic, or acidic conditions is given below, combined with the work-up in case the protecting group reacted $(R)$ or remained unaffected $(+)$ under the tested conditions. Reactions were typically performed on a $100-200 \mathrm{mg}$ scale.

Weak nucleophile (NaI). In a $20 \mathrm{ml}$ screw cap vial that contained a stirring bar, PBSPMA was dissolved in DMSO $\left(60 \mathrm{mg} \mathrm{ml}^{-1}\right)$, and 3 eq. NaI was added per monomer unit. The homogeneous solution was heated at $70^{\circ} \mathrm{C}$ for $20 \mathrm{~h}$, and turned dark brown over time. After cooling down, the reaction mixture was precipitated into a large excess 
ethanol/pentane (2/1), filtered using a glass filter funnel (pore size 4 ), and the precipitate was washed thoroughly with ethanol/pentane $(1 / 1)$ until the filtrate became colorless. A final wash with pentane was performed. Drying of the product in vacuo $\left(40^{\circ} \mathrm{C}\right)$ afforded the sodium salt of PSPMA as a pink powder.

In case the polymer remained unaffected by $\mathrm{NaI}$ treatment, the protected polymer (PPhSPMA, PFSPMA, and PNSPMA) was recovered by precipitation into hexane/isopropanol (2/1) and washing the precipitate with a 1/1 mixture to remove the excess NaI.

Strong nucleophile $\left(\mathrm{NaN}_{3}\right)$. A $20 \mathrm{ml}$ screw cap vial was charged with PNSPMA and 3 eq. $\mathrm{NaN}_{3}$ with respect to the number of monomer units. Both were dissolved in DMSO (50 mg ml ${ }^{-1}$ PNSPMA), and the resulting colorless solution was heated at $130{ }^{\circ} \mathrm{C}$ for $20 \mathrm{~h}$. The reaction mixture was precipitated in undiluted form into a large excess pentane/ethanol (1/1), filtered (pore size 4 ), and washed thoroughly with ethanol to remove the excess $\mathrm{NaN}_{3}$, further washed with a $1 / 1$ pentane/ethanol mixture, and finally a portion of pentane. Drying of the product in vacuo $\left(40^{\circ} \mathrm{C}\right)$ afforded the sodium salt of PSPMA as a white powder.

PPhSPMA and PFSPMA (both reacting) could be recovered by precipitation into isopropanol/hexane $(1 / 1)$, followed by washing with ethanol to remove the excess $\mathrm{NaN}_{3}$.

Basic conditions (NaOH). In a $20 \mathrm{ml}$ screw cap vial, PPhSPMA was dissolved in DMSO (40 mg ml $\mathrm{m}^{-1}$ ) and $2.5 \mathrm{eq}$. (with respect to the number of monomer units) of a $2 \mathrm{M} \mathrm{NaOH}$ solution in methanol was added. The pink solution turned colorless instantaneously, and was allowed to stir for $20 \mathrm{~h}$ at room temperature. The reaction mixture was precipitated in undiluted form into a large excess of ethanol/pentane (1/1), filtered (pore size 4), washed with a $1 / 1$ pentane/ethanol mixture, and finally with a portion of pentane. Drying of the product in vacuo $\left(40^{\circ} \mathrm{C}\right)$ afforded the sodium salt of PSPMA as a white powder.

PNSPMA (unaffected by $\mathrm{NaOH}$ ) was recovered by precipitation into water, followed by centrifugation. The obtained polymer pellet was washed with isopropanol/hexane $(1 / 1)$ and hexane. The product of PFSPMA (reacting) after treatment with base was isolated by removing DMSO through distillation, and washing the resulting solid with hexane/isopropanol (1/1) and hexane.

Acidic conditions (HBr). A $4 \mathrm{ml}$ vial equipped with a small stirring bar was charged with PBSPMA, to which a 2/1 mixture of 1,4-dioxane/ $\mathrm{HBr}\left(48 \mathrm{wt} \%\right.$ in $\mathrm{H}_{2} \mathrm{O}$ ) was added. The dispersion $\left(70 \mathrm{mg} \mathrm{ml}^{-1}\right)$ was stirred and heated at $100{ }^{\circ} \mathrm{C}$ for $20 \mathrm{~h}$; a clear homogeneous solution was obtained after $2 \mathrm{~h}$. Next, the reaction mixture was precipitated into a solution of $1 \mathrm{~g} \mathrm{NaI}$ in $40 \mathrm{ml}$ ethanol. After filtration (pore size 4) the precipitate was washed with more ethanol, ethanol/pentane (1/1), and finally a portion of pentane. Drying of the product in vacuo $\left(40^{\circ} \mathrm{C}\right)$ afforded the sodium salt of PSPMA as an off-white powder.

Dispersions of protected poly(3-sulfopropyl methacrylates) that were not affected by acid remained cloudy throughout the reaction. PNSPMA and PPhSPMA were recovered by diluting the reaction mixture with acetone, followed by precipitation into iso- 
propanol/hexane (1/1). For PFSPMA, the majority of solvent and acid was removed by rotary evaporation, with the remainder being washed with water. The resulting solid was redissolved in THF, and precipitated into ethanol/pentane (1/1).

Orthogonal deprotection. Selective deprotection of PBSPMA-containing diblock copolymers through NaI treatment was performed using the same procedure as for the homopolymers. Concentrations were adapted by taking the composition of the block copolymer into account (i.e., $60 \mathrm{mg} \mathrm{ml}^{-1}$ PBSPMA and 3 eq. NaI). Precipitation was performed in ethanol/pentane (1/1). NaI-treated diblock copolymers were obtained as pink powders. Similarly, for PPhSPMA-containing diblock copolymers the concentrations were adapted as well (i.e., $40 \mathrm{mg} \mathrm{ml}^{-1} \mathrm{PPhSPMA}$ and 2.5 eq. NaI). The orthogonally deprotected copolymer was isolated by precipitation into ethanol/pentane $(1 / 1)$, giving a white powder after washing and drying. Removal of the protecting group of the second block was achieved by following the homopolymer deprotection routes: $\mathrm{NaOH}$ for PPhSPMA (40 mg ml${ }^{-1}, 2.5$ eq. $\mathrm{NaOH}$ ) and $\mathrm{NaN}_{3}$ for PNSPMA (50 mg ml${ }^{-1}, 3$ eq. $\mathrm{NaN}_{3}$ ), both resulting in white powders after washing and drying.

\subsection{Sample preparation}

Micellar aggregates of the partially deprotected diblock copolymers were prepared via the solvent addition method. ${ }^{2}$ First, $18 \mathrm{mg}$ of the diblock copolymer was weighted into a $20 \mathrm{ml}$ screw cap vial, and subsequently molecularly dissolved in $2 \mathrm{ml}$ DMSO containing $0.1 \mathrm{M} \mathrm{KNO}_{3}$. Complete dissolution could be achieved by carefully heating the solution with a heat gun, and shaking the vial overnight at room temperature. Next, 20 drops of a $\mathrm{H}_{2} \mathrm{O} / \mathrm{DMSO}(1 / 1)$ solvent mixture were added slowly, then $10 \mathrm{ml}_{2} \mathrm{O}$ was added dropwise, and the clear solution was further diluted with another portion of water (6 $\mathrm{ml})$. Final composition: $1.0 \mathrm{mg} \mathrm{ml}{ }^{-1}, 11 \mathrm{mM} \mathrm{KNO}_{3}$, and $13 \mathrm{wt} \%$ DMSO $(\eta=1.12 \mathrm{cP}$, $n=1.35) .{ }^{3}$ All solvents were filtered three times before use.

Negatively stained TEM samples were prepared by depositing a drop of the polymer aggregate solution onto a carbon-coated and glow-discharged 400 mesh copper grid. The excess liquid was removed after 1 min using filter paper. Next, the wet sample was washed with a few $\mu$ l of an aqueous uranyl acetate solution (2 wt $\%$ ), immediately blotted, and subsequently stained for $1 \mathrm{~min}$ with a drop of the same uranyl acetate solution. After having removed the excess staining agent with a filter paper, the sample was dried at room temperature before imaging.

\subsection{Characterization}

${ }^{1} \mathrm{H}$ and ${ }^{13} \mathrm{C}$ nuclear magnetic resonance (NMR) spectra were recorded at room temperature on either a Varian VXR-400 or Agilent 400-MR spectrometer. Chemical shifts $(\delta)$ are reported in parts per million $(\mathrm{ppm})$ relative to the residual solvent peak $\left(\mathrm{CDCl}_{3}\right.$, DMSO- $\mathrm{d}_{6}$, methanol- $\mathrm{d}_{4}$, or $\left.\mathrm{D}_{2} \mathrm{O}\right)$.

Fourier transform infrared spectroscopy (FTIR) was carried out on a Bruker Vertex 70 instrument at room temperature in attenuated total reflection (ATR) mode. 
Gel permeation chromatography (GPC) was performed on a Viscotek GPCmax system equipped with a TDA 302 triple detector array (refractive index, viscosity, and light scattering) and two analytical columns (Agilent Technologies PolarGel-M and PolarGel-L, 30 $\mathrm{cm} / 8 \mu \mathrm{m})$. Both the columns and detectors were held at $50{ }^{\circ} \mathrm{C} . N, N$-dimethylformamide (DMF) containing $0.01 \mathrm{M} \mathrm{LiBr}$ was used as eluent at a flow rate of $1.0 \mathrm{ml} \mathrm{min}{ }^{-1}$. Narrow PMMA standards were used for calibration of the system and samples were filtered over a $0.2 \mu \mathrm{m}$ PTFE filter prior to injection. Molecular weights of the homopolymers were calculated by applying either conventional calibration, universal calibration, or light scattering (Table S1) using Viscotek OmniSEC software. $M_{n \text {,calc }}$ is the calculated molecular weight based on the monomer conversion $\left({ }^{1} \mathrm{H}-\mathrm{NMR}\right)$ and the theoretical maximum molecular weight (monomer/CTA ratio). Molecular weights of the diblock copolymers were determined by combining the molecular weight of the macro-CTA and the composition of the copolymer $\left({ }^{1} \mathrm{H}-\mathrm{NMR}\right)$.

Thermogravimetric analysis (TGA) was performed on a TA Instruments TGA 5500 under a continuous nitrogen flow. Samples were heated from 30 to $700{ }^{\circ} \mathrm{C}$ at a heating rate of 2 or $10^{\circ} \mathrm{C} \mathrm{min}^{-1}$.

Differential scanning calorimetry (DSC) measurements were conducted on a TA Instruments DSC Q1000 under a nitrogen atmosphere in the modulated mode $\left(0.5^{\circ} \mathrm{C}\right.$, period $60 \mathrm{~s})$. The samples were heated to $130^{\circ} \mathrm{C}$ and cooled back to $-80^{\circ} \mathrm{C}$ at a rate of $2{ }^{\circ} \mathrm{C}$ $\min ^{-1}$, with the second heating cycle being used for analysis.

Hydrodynamic radii $\left(R_{h}\right)$, polydispersity indices (PDIs), and zeta potentials $(\zeta)$ of the micellar aggregates were determined at $25^{\circ} \mathrm{C}$ using a Malvern Zetasizer Ultra. This instrument is equipped with a $10 \mathrm{~mW}$ HeNe laser $(\lambda=632.8 \mathrm{~nm})$ with the scattering being detected at a fixed backscatter angle of $173^{\circ}$ (non-invasive back scatter; NIBS). Acquisition times were determined automatically and recorded data were averaged over three consecutive runs.

Negatively stained samples were analyzed on a Philips CM12 transmission electron microscope (TEM) that was equipped with a tungsten filament and operated at an accelerating voltage of $120 \mathrm{kV}$. Images were recorded on a Gatan slow-scan CCD camera, and the raw data were subsequently processed by using ImageJ software. 


\section{Polymer synthesis}

Molecular weights as estimated by gel permeation chromatography (GPC) seem to deviate substantially from the theoretical values (based on the monomer conversion), but it should be remarked that molecular weights are reported as PMMA-equivalents (i.e., $M_{n}$ calculated via conventional calibration). Surprisingly, universal calibration always resulted in a more than double overestimation (Table S1), regardless of the monomer type. A plausible explanation for this unexpected behavior is that the assumption of the hydrodynamic radius $R_{h}$ being proportional to $[\eta] \cdot M$ is incorrect for protected PSPMAs in DMF. ${ }^{4,5}$ More realistic values were obtained by light scattering (Table S1), but this method still resulted in an overestimation. Weak scattering of these samples due to the low refractive index increment in DMF $\left(\mathrm{d} n / \mathrm{d} c<0.1 \mathrm{ml} \mathrm{g}^{-1}\right)$ possibly causes overrepresentation of the higher molecular weight fractions. One of the samples (PBSPMA-1), however, was previously measured by light scattering in hexafluoroisopropanol (HFIP; $\left.\mathrm{d} n / \mathrm{d} c=0.184 \mathrm{ml} \mathrm{g}^{-1}\right)$, and was found to adopt a molecular weight very close to the theoretical value $\left(M_{n}=11.1 \mathrm{~kg} \mathrm{~mol}^{-1}, \mathrm{Ð}=1.15\right)$. Therefore, we are convinced that the observed deviation is caused by the measurement, and not the polymerization itself. Still, as conventional calibration is widely accepted by the polymer community, in the main text the molecular weights of all polymers are reported as PMMA-equivalents.

\begin{tabular}{lcccccccc}
\hline Polymer & $M_{n, \text { calc }}$ & Conv. $\left(M_{n}\right)$ & Conv. (Đ) & Uni $\left(M_{n}\right)$ & Uni (Đ) & LS $\left(M_{n}\right)$ & LS (Đ) & $\mathrm{d} n / \mathrm{d} c(\mathrm{ml} / \mathrm{g})$ \\
\hline PBSPMA-1 & 8.82 & 14.7 & 1.15 & 35.7 & 1.13 & 10.8 & 1.56 & 0.0486 \\
PBSPMA-2 & 27.7 & 40.4 & 1.11 & 93.8 & 1.08 & 42.4 & 1.21 & 0.0490 \\
PBSPMA-3 & 63.7 & 85.6 & 1.27 & 167.8 & 1.34 & 116.1 & 1.15 & 0.0478 \\
PBSPMA-4 & 110.3 & 142.7 & 1.38 & 262.7 & 1.49 & 233.9 & 1.16 & 0.0479 \\
PPhSPMA-1 & 27.7 & 21.6 & 1.13 & 39.4 & 1.09 & 39.1 & 1.24 & 0.0823 \\
PPhSPMA-2 & 55.7 & 53.2 & 1.19 & 95.8 & 1.23 & 113.2 & 1.14 & 0.0794 \\
PFSPMA-1 & 27.2 & 28.0 & 1.10 & 77.8 & 1.05 & - & - & 0.0047 \\
PNSPMA-1 & 21.6 & 19.7 & 1.12 & 36.8 & 1.07 & 32.1 & 1.16 & 0.0485 \\
\hline
\end{tabular}

Table S1: Comparison of different methods for the GPC-analysis of protected poly(3sulfopropyl methacrylate) homopolymers: conventional calibration (Conv.), universal calibration (Uni), and light scattering (LS). PFSPMA could not be characterized by LS due to its weak scattering in DMF. Molecular weights are reported in $\mathrm{kg} \mathrm{mol}^{-1} . M_{n \text {,calc }}$ is the theoretical molecular weight which is based on the CTA/monomer ratio and the conversion. 


\begin{tabular}{lccccccccc}
\hline Polymer & {$[\mathrm{CTA}]$} & {$[\mathrm{AIBN}]$} & {$[\mathrm{AIBN}] /[\mathrm{CTA}]$} & {$[\mathrm{M}]$} & $t_{r}(\mathrm{~h})$ & Conv. $(\%)$ & $M_{n}$ & $M_{n, \mathrm{GPC}}$ & Đ \\
\hline PNeo-b-PPh & 14.6 & 1.63 & $1 / 9.2$ & 1.10 & 21 & 95 & 39.9 & 38.0 & 1.17 \\
PiBu- $b$-PPh & 10.8 & 1.06 & $1 / 10.3$ & 1.10 & 21 & 96 & 59.7 & 62.1 & 1.19 \\
PiBu- $b$-PNeo & 10.7 & 1.09 & $1 / 9.9$ & 1.17 & 23 & 96 & 60.1 & 65.9 & 1.20 \\
\hline
\end{tabular}

Table S2: Reaction conditions for the preparation of orthogonally protected diblock copolymers. CTA and AIBN concentrations are in mM, monomer concentrations in $\mathrm{M}$, and molecular weights are reported in $\mathrm{kg} \mathrm{mol}^{-1}$. In case a PBSPMA macro-CTA was chain-extended, its theoretical molecular weight was used for the calculation of the concentrations and final block copolymer molecular weight.

\section{Results and discussion}

- Figures S1 - S4: ${ }^{1} \mathrm{H}-\mathrm{NMR}$ and ${ }^{13} \mathrm{C}-\mathrm{NMR}$ spectra of protected monomers

- Figures S5 - S6: ${ }^{1} \mathrm{H}-\mathrm{NMR}$ spectra of protected homopolymers

- Figure S7: Thermal analysis of protected homopolymers (DSC and TGA)

- Figure S8: TGA measurements of PBSPMA and PPhSPMA (2 vs $\left.10^{\circ} \mathrm{C} \mathrm{min}{ }^{-1}\right)$

- Figures S9 - S14: ${ }^{1} \mathrm{H}-\mathrm{NMR}$ data of protected polymers after nucleophilic, acidic and basic treatment

- Figure S15: FTIR spectrum of $\mathrm{NaN}_{3}$-treated PPhSPMA

- Figures S16 - S19: ${ }^{1} \mathrm{H}-\mathrm{NMR}$ data of protected PSPMAs after nucleophilic, acidic and basic treatment

- Figures S20 - S22: ${ }^{1} \mathrm{H}-\mathrm{NMR}$ spectra and GPC elugrams of PMMA after deprotection model reactions

- Table S3: DLS data of as-prepared and diluted solutions

- Figures S23: TEM images recorded at a lower magnification 
a)

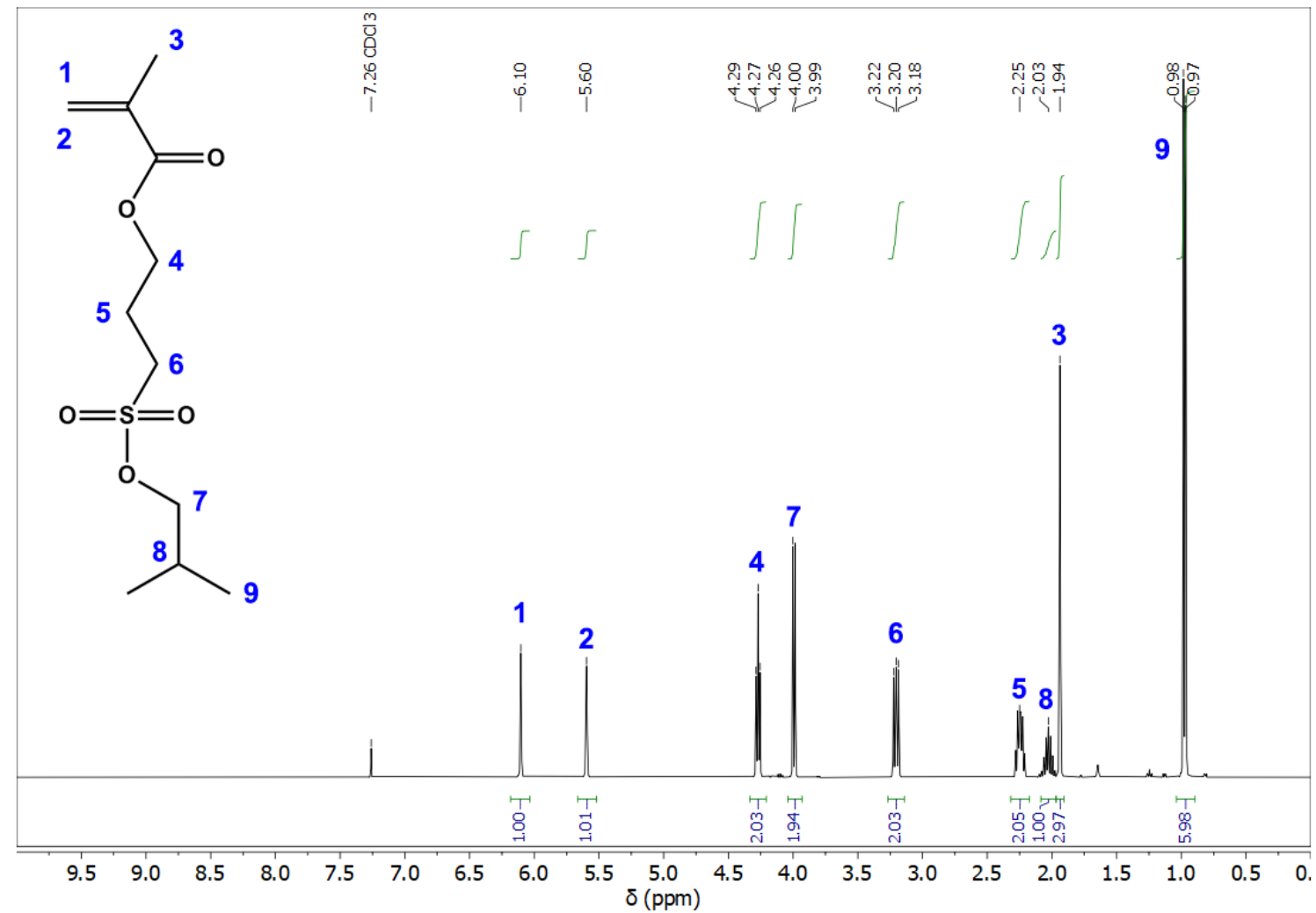

b)

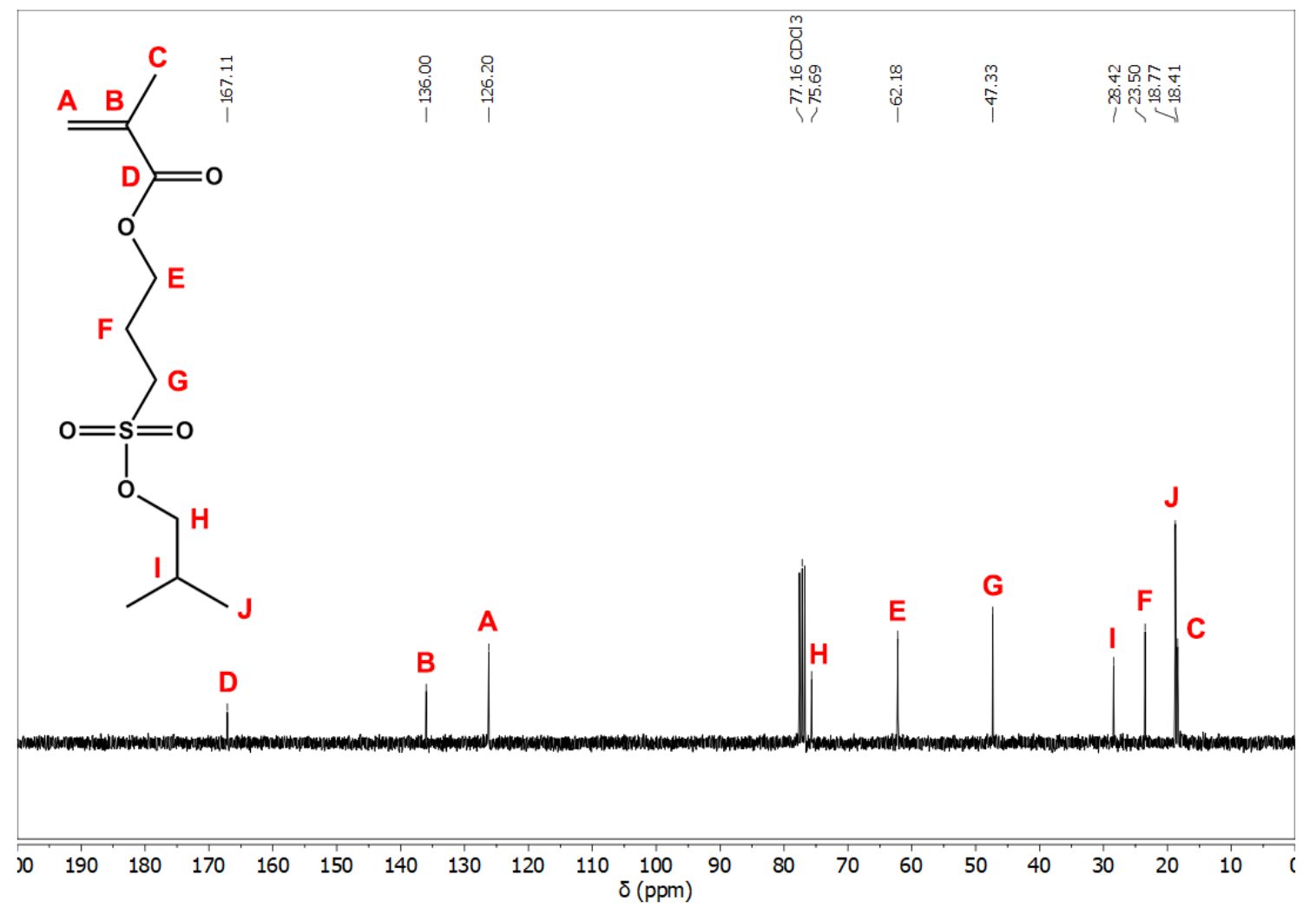

Figure S1: (a) ${ }^{1} \mathrm{H}-\mathrm{NMR}$ and (b) ${ }^{13} \mathrm{C}-\mathrm{NMR}$ spectra $\left(\mathrm{CDCl}_{3}\right)$ of purified 3(isobutoxysulfonyl)propyl methacrylate (BSPMA). 
a)

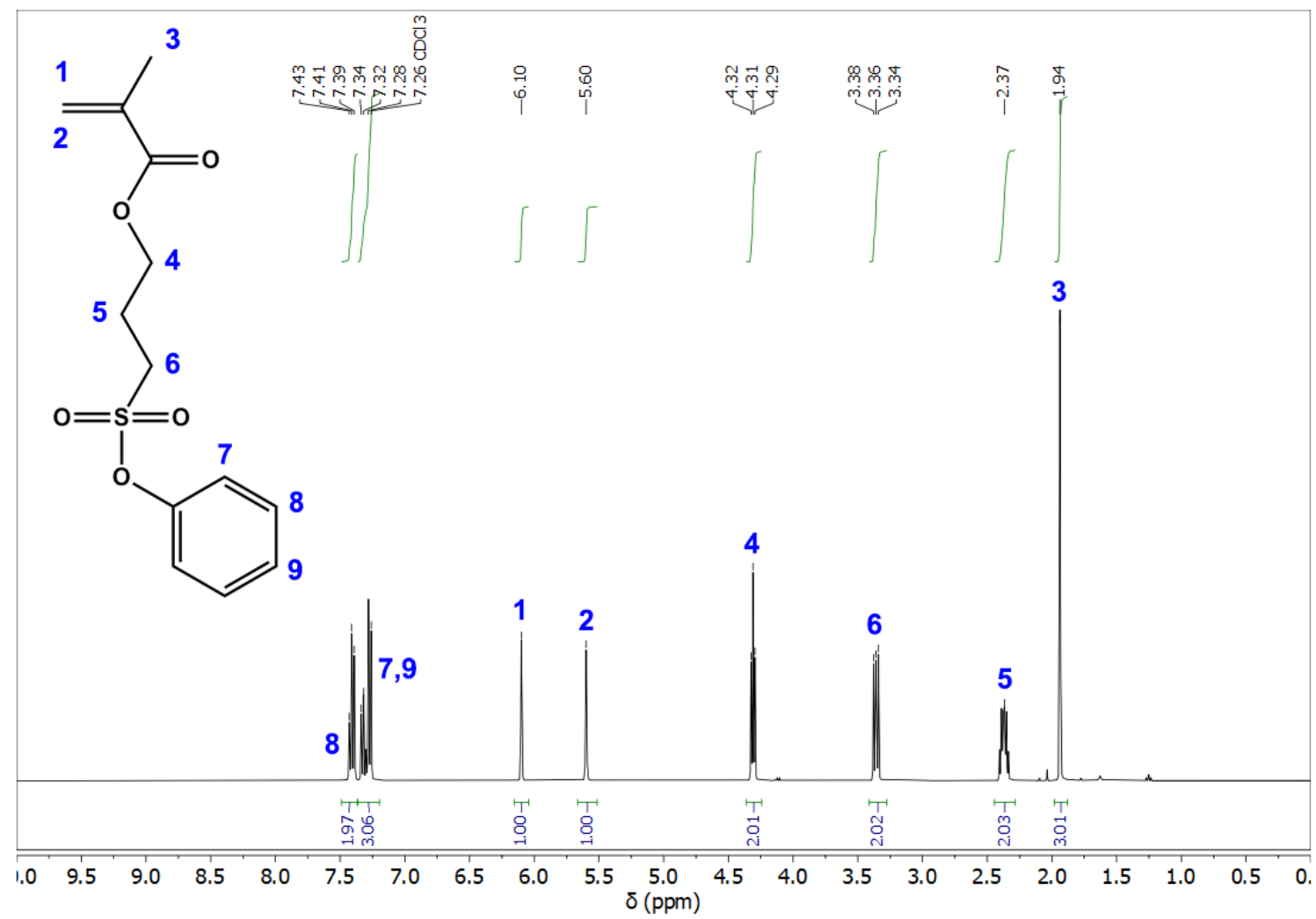

b)

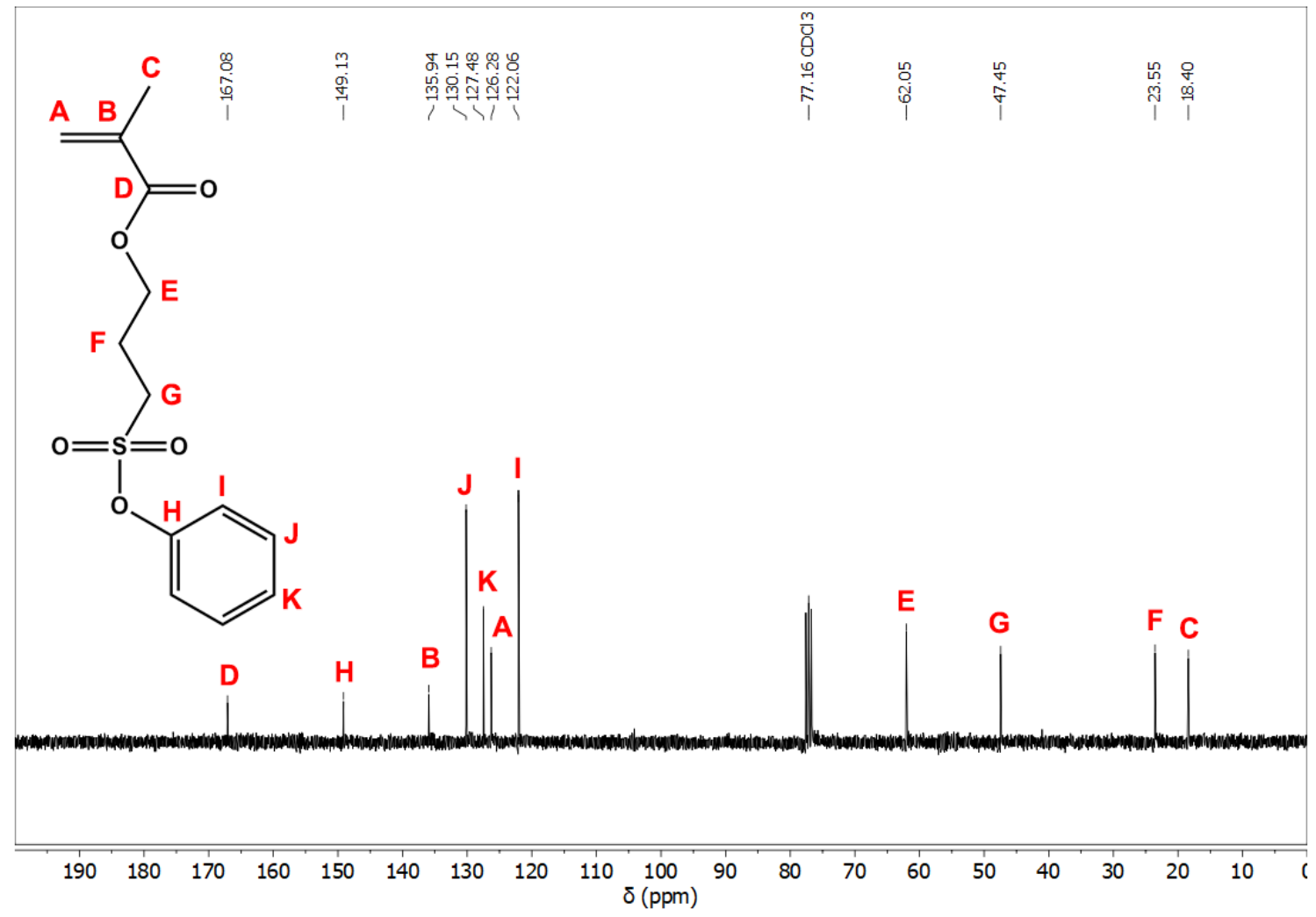

Figure S2: (a) ${ }^{1} \mathrm{H}-\mathrm{NMR}$ and (b) ${ }^{13} \mathrm{C}-\mathrm{NMR}$ spectra $\left(\mathrm{CDCl}_{3}\right)$ of purified 3(phenoxysulfonyl)propyl methacrylate (PhSPMA). 
a)

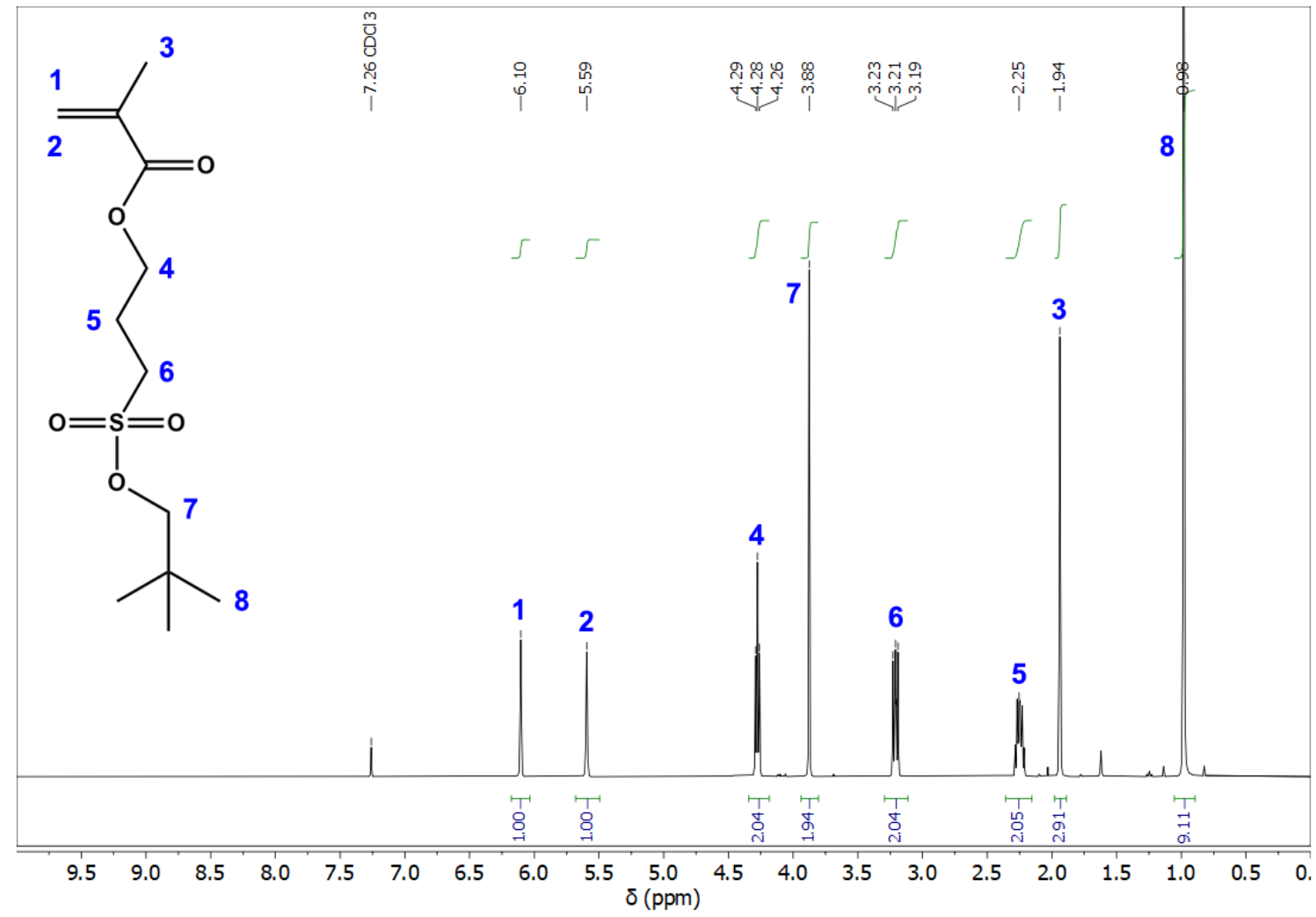

b)

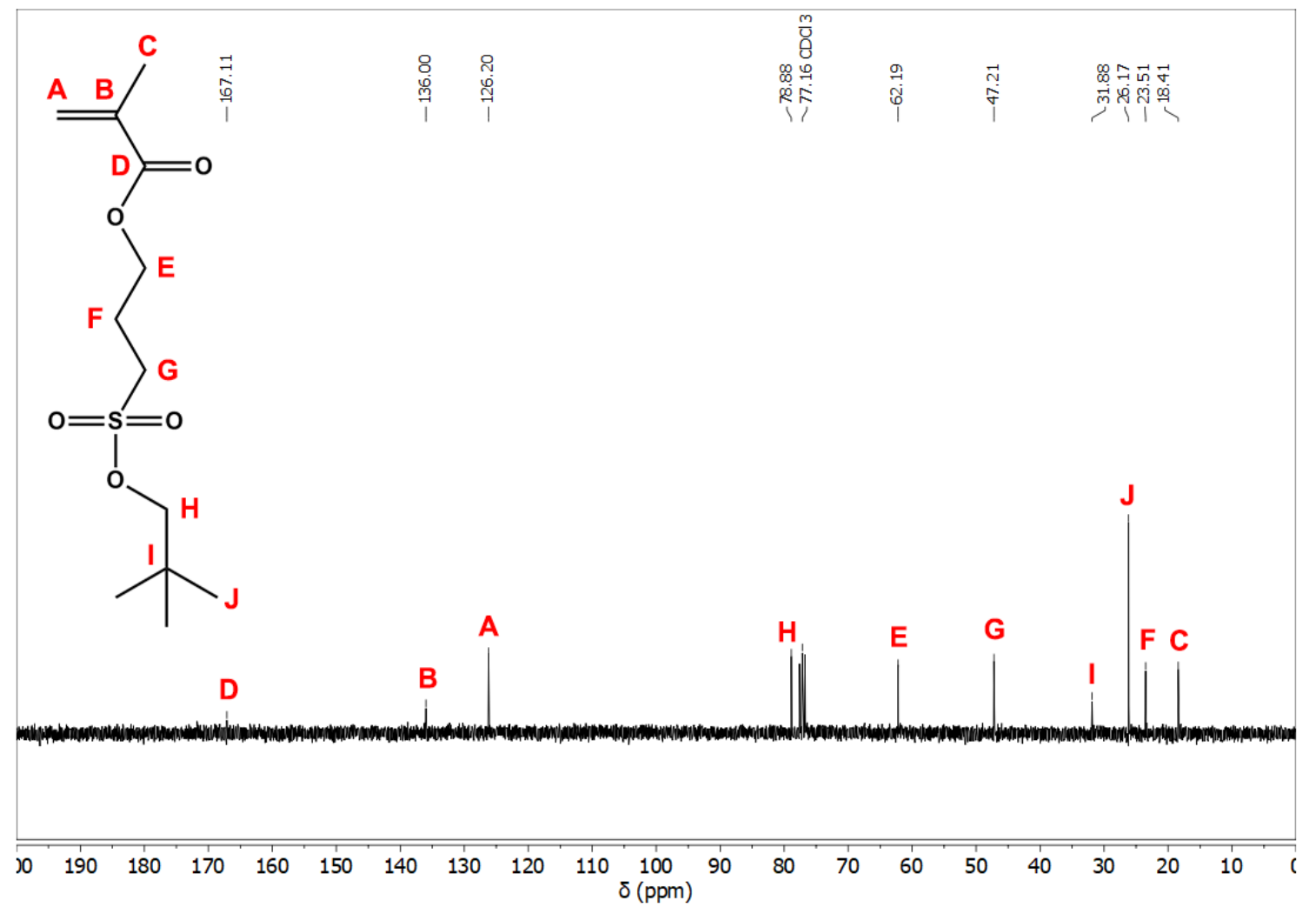

Figure S3: (a) ${ }^{1} \mathrm{H}-\mathrm{NMR}$ and (b) ${ }^{13} \mathrm{C}-\mathrm{NMR}$ spectra $\left(\mathrm{CDCl}_{3}\right)$ of purified 3(neopentyloxysulfonyl)propyl methacrylate (NSPMA). 
a)

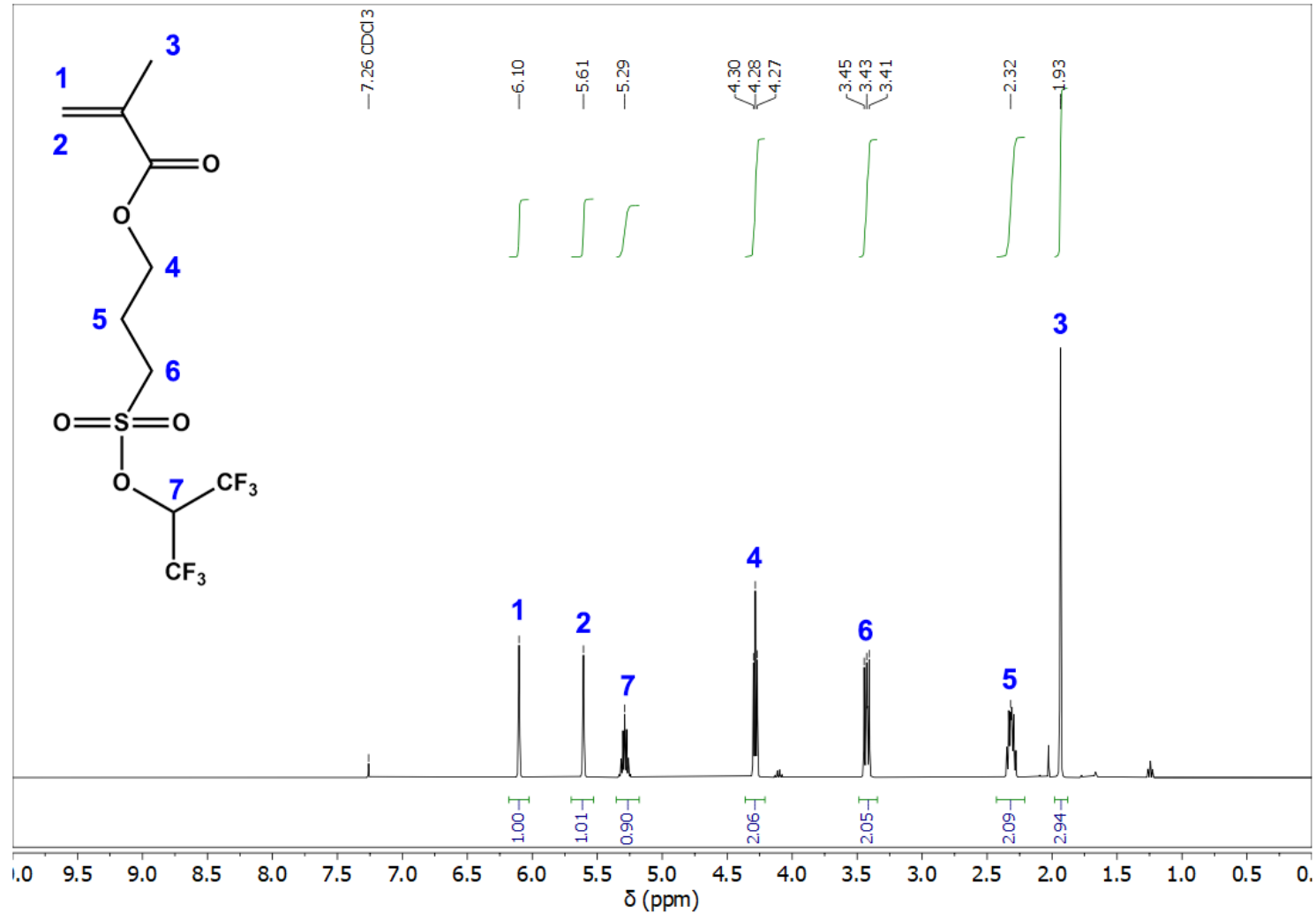

b)

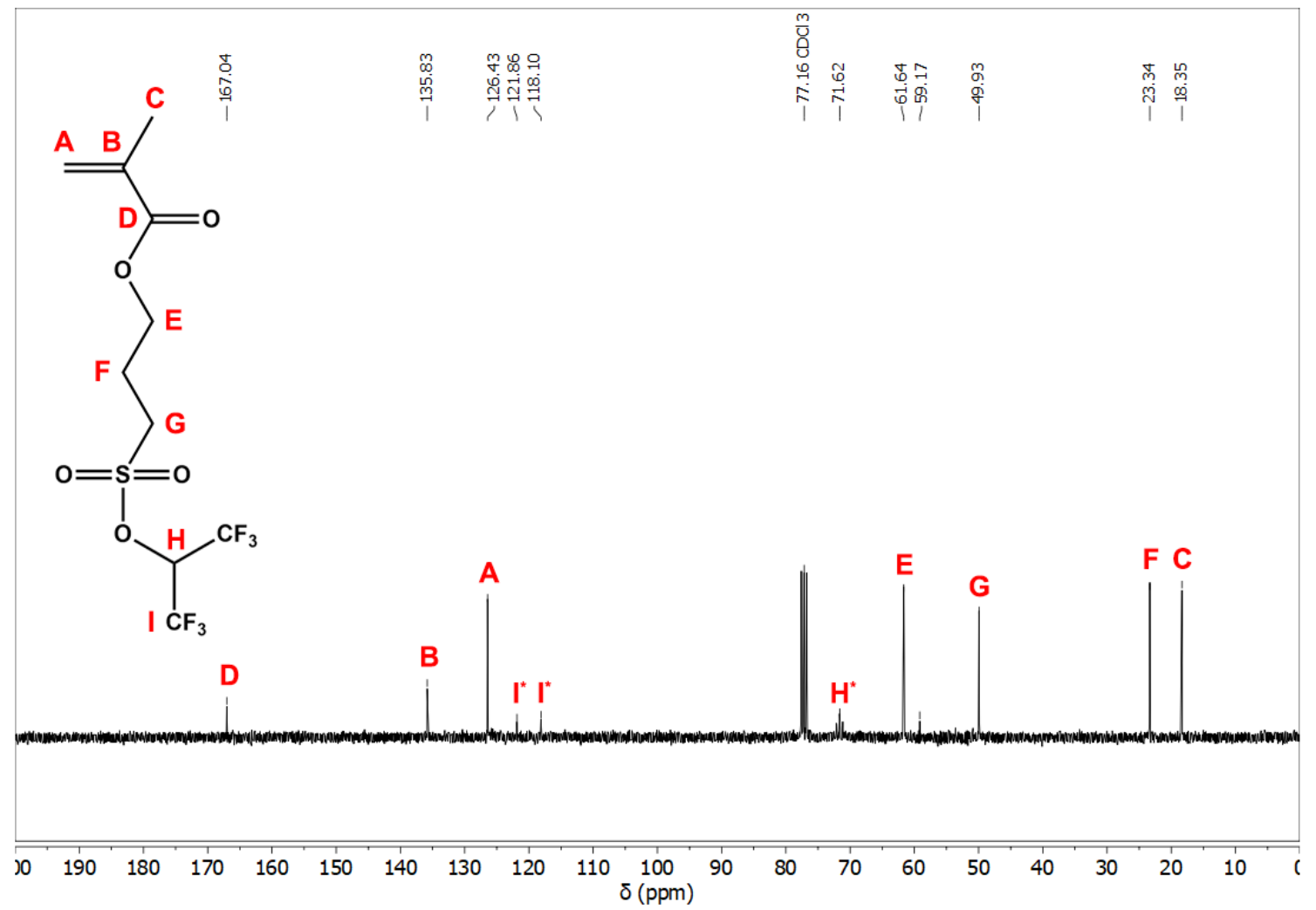

Figure S4: (a) ${ }^{1} \mathrm{H}-\mathrm{NMR}$ and (b) ${ }^{13} \mathrm{C}-\mathrm{NMR}$ spectra $\left(\mathrm{CDCl}_{3}\right)$ of purified $3-(((1,1,1,3,3,3-$ hexafluoropropan-2-yl)oxy)sulfonyl)propyl methacrylate (FSPMA). In (b) ${ }^{13} \mathrm{C}^{19}{ }^{19} \mathrm{~F}$ coupling results in a complex splitting pattern: $\mathrm{I}^{*}\left(\mathrm{CF}_{3}\right.$; part of quartet) and $\mathrm{H}^{*}$ (multiplet; ${ }^{13} \mathrm{C}-{ }^{19} \mathrm{~F}$ coupling over two bonds). 
a)

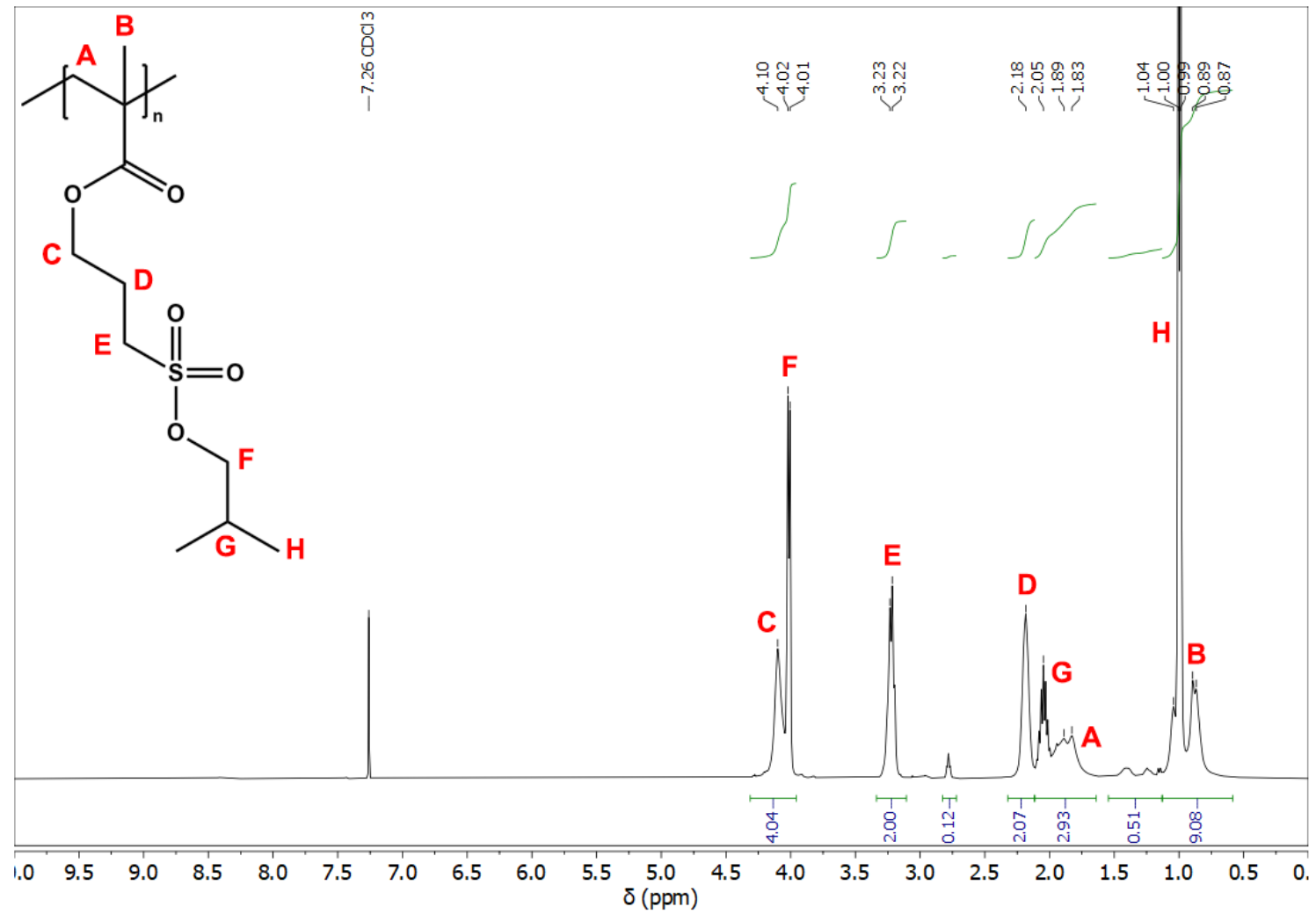

b)

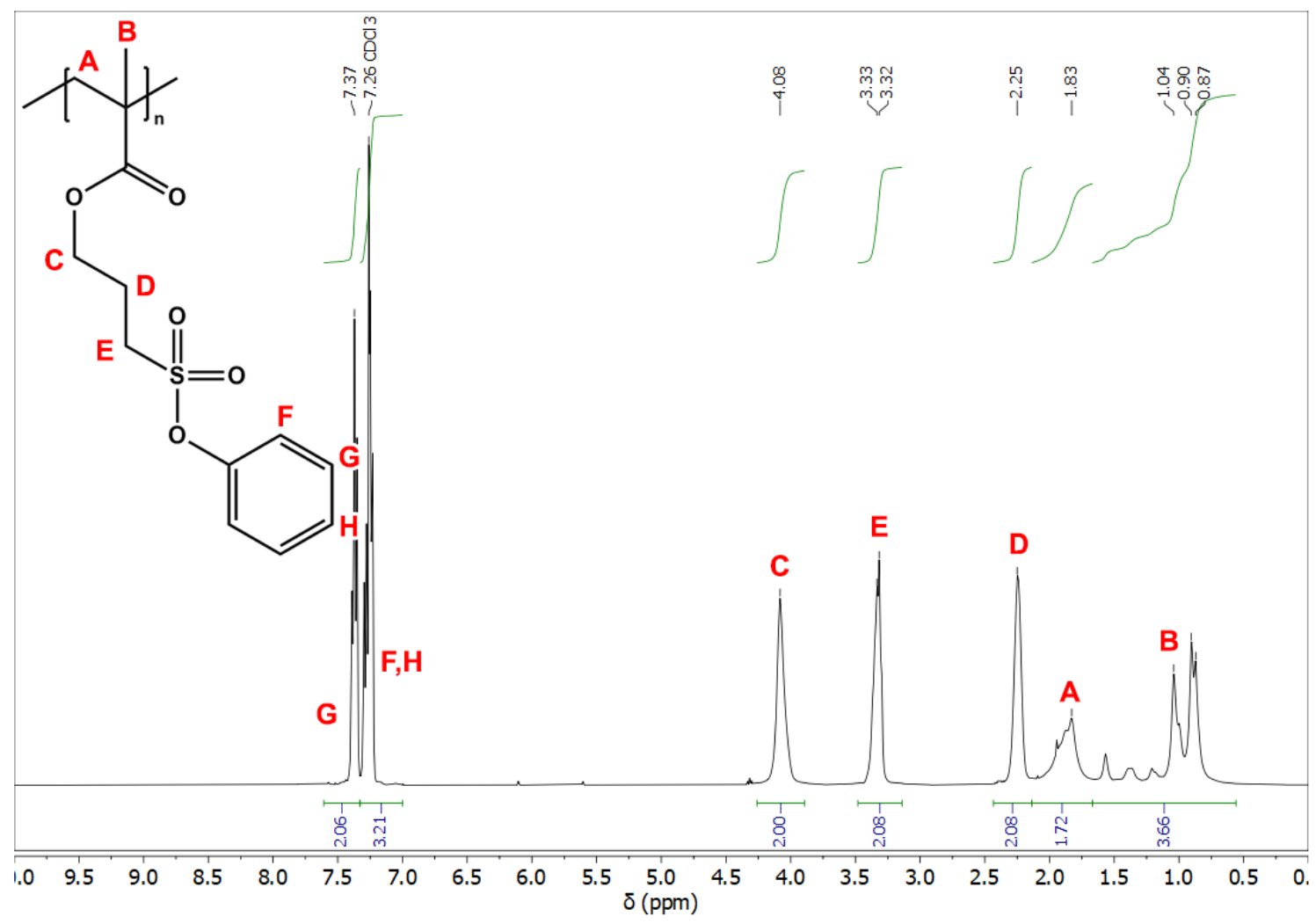

Figure S5: ${ }^{1} \mathrm{H}-\mathrm{NMR}$ spectra of (a) isobutyl-protected (PBSPMA) and (b) phenyl-protected poly(3-sulfopropyl methacrylate) (PPhSPMA) after purification. Both polymers were measured in $\mathrm{CDCl}_{3}$. 
a)

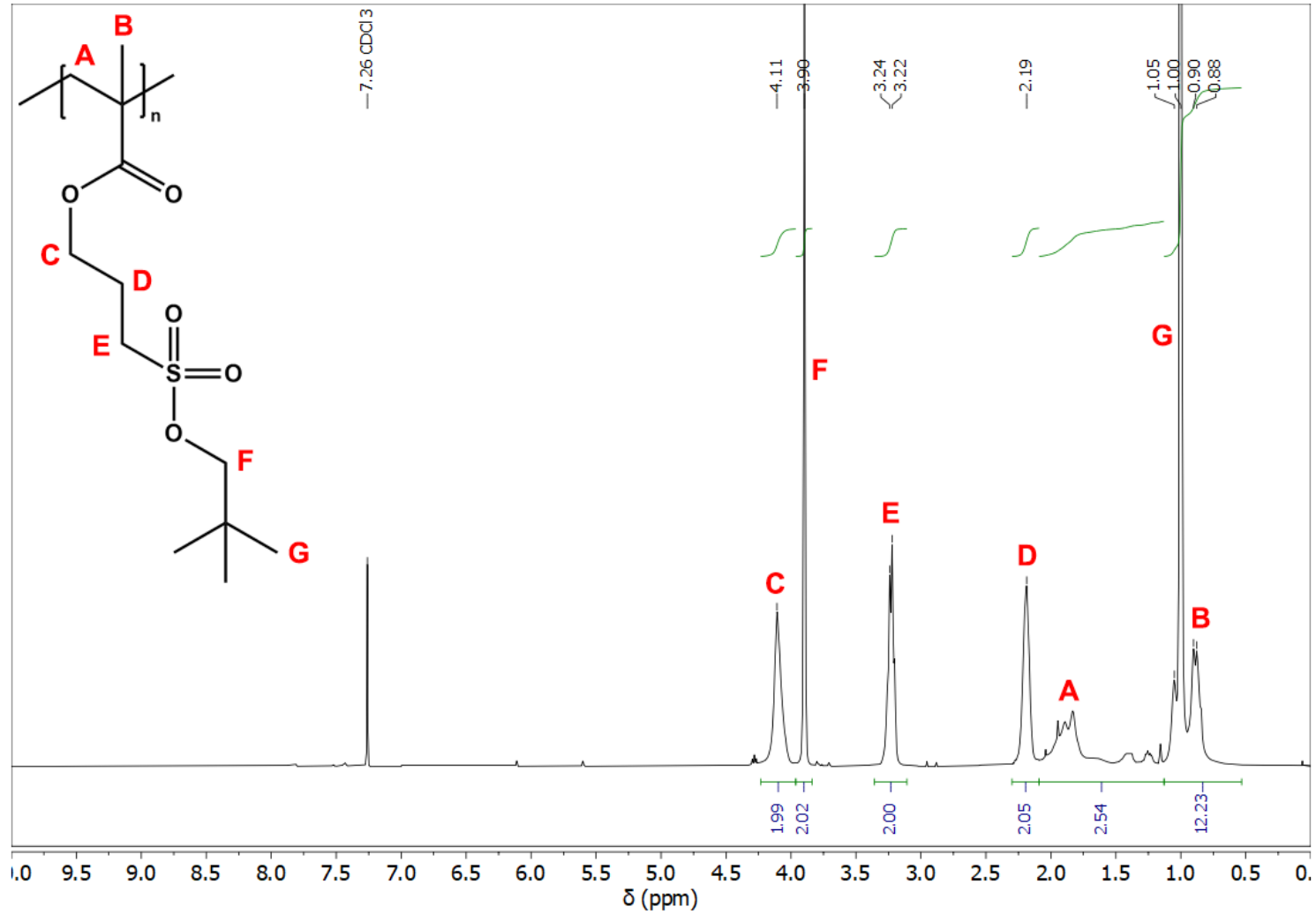

b)

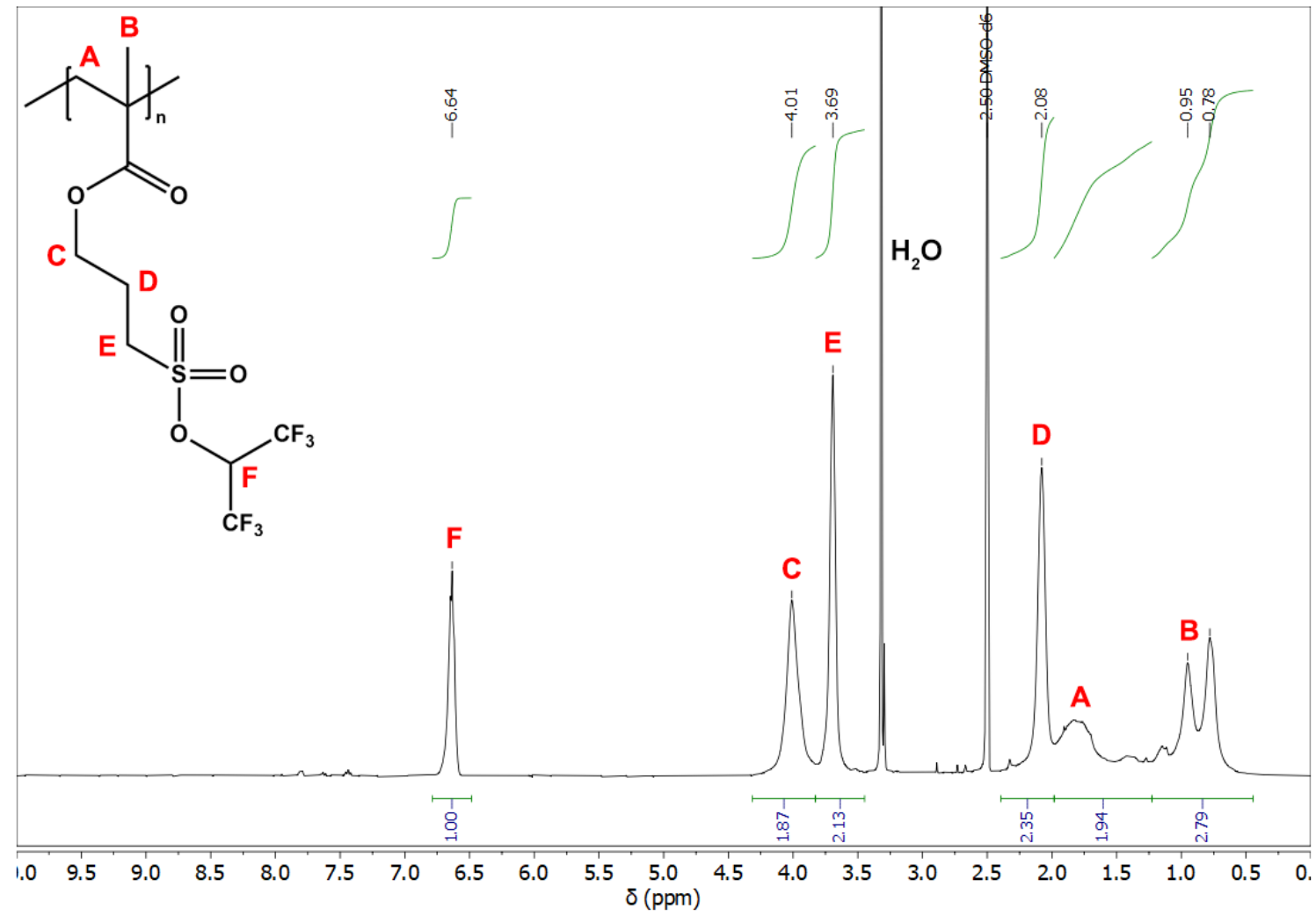

Figure S6: ${ }^{1} \mathrm{H}-\mathrm{NMR}$ spectra of (a) neopentyl-protected (PNSPMA) and (b) hexafluoroisopropyl-protected poly(3-sulfopropyl methacrylate) (PFSPMA) after purification. PNSPMA was recorded in $\mathrm{CDCl}_{3}$ and PFSPMA in DMSO- $\mathrm{d}_{6}$. 

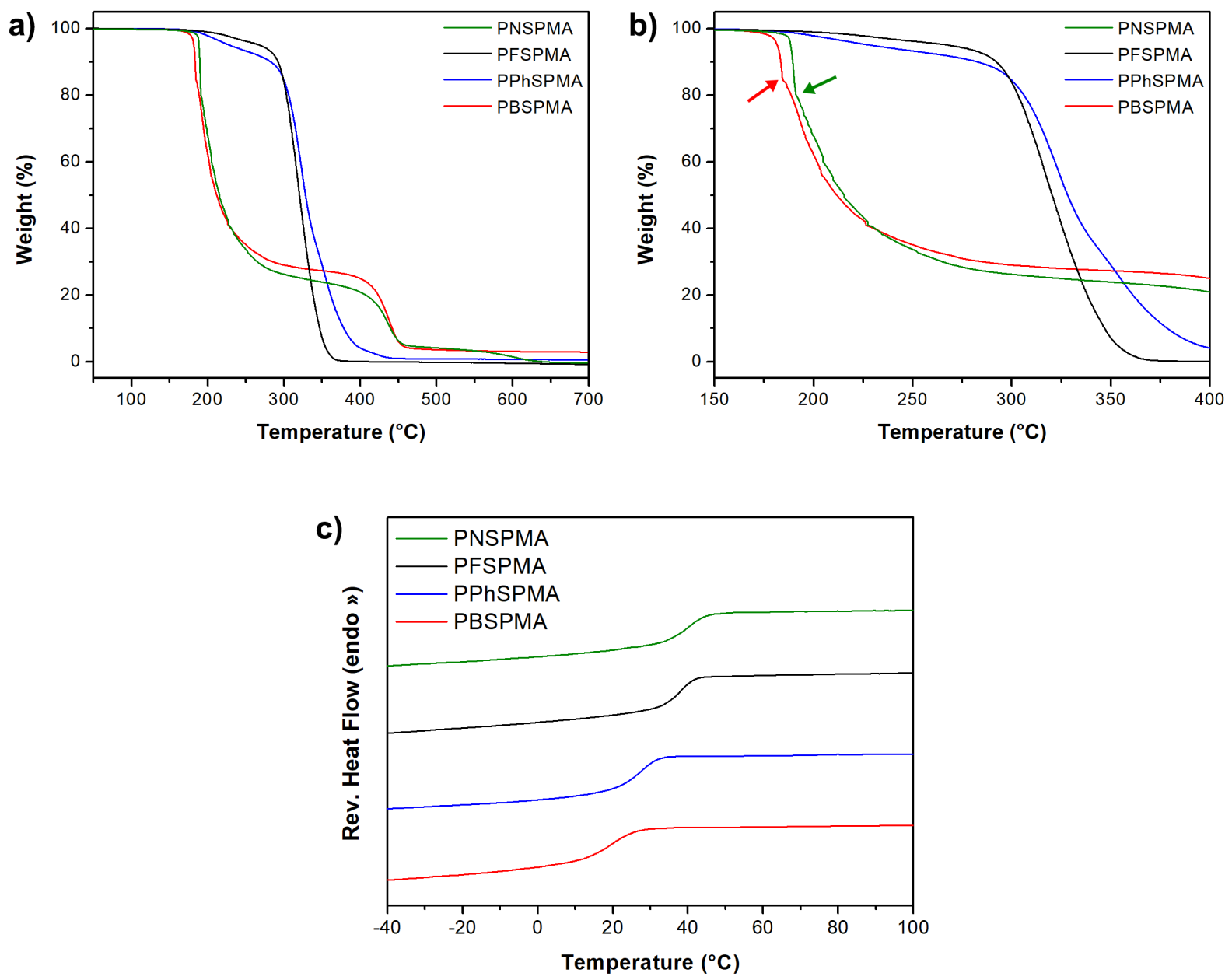

Figure S7: Thermal analysis of the protected poly(3-sulfopropyl methacrylates). (a) Full and (b) zoomed-in degradation profiles obtained through thermogravimetric analysis (TGA). Arrows in (b) indicate the loss of the protecting groups ( 20\%) of PBSPMA and PNSPMA. (c) Glass transition temperatures determined by differential scanning calorimetry (DSC): PBSPMA $\left(T_{g}=19^{\circ} \mathrm{C}\right)$, PPhSPMA $\left(T_{g}=27^{\circ} \mathrm{C}\right)$, PFSPMA $\left(T_{g}=38^{\circ} \mathrm{C}\right)$, and PNSPMA $\left(T_{g}=40^{\circ} \mathrm{C}\right)$. 

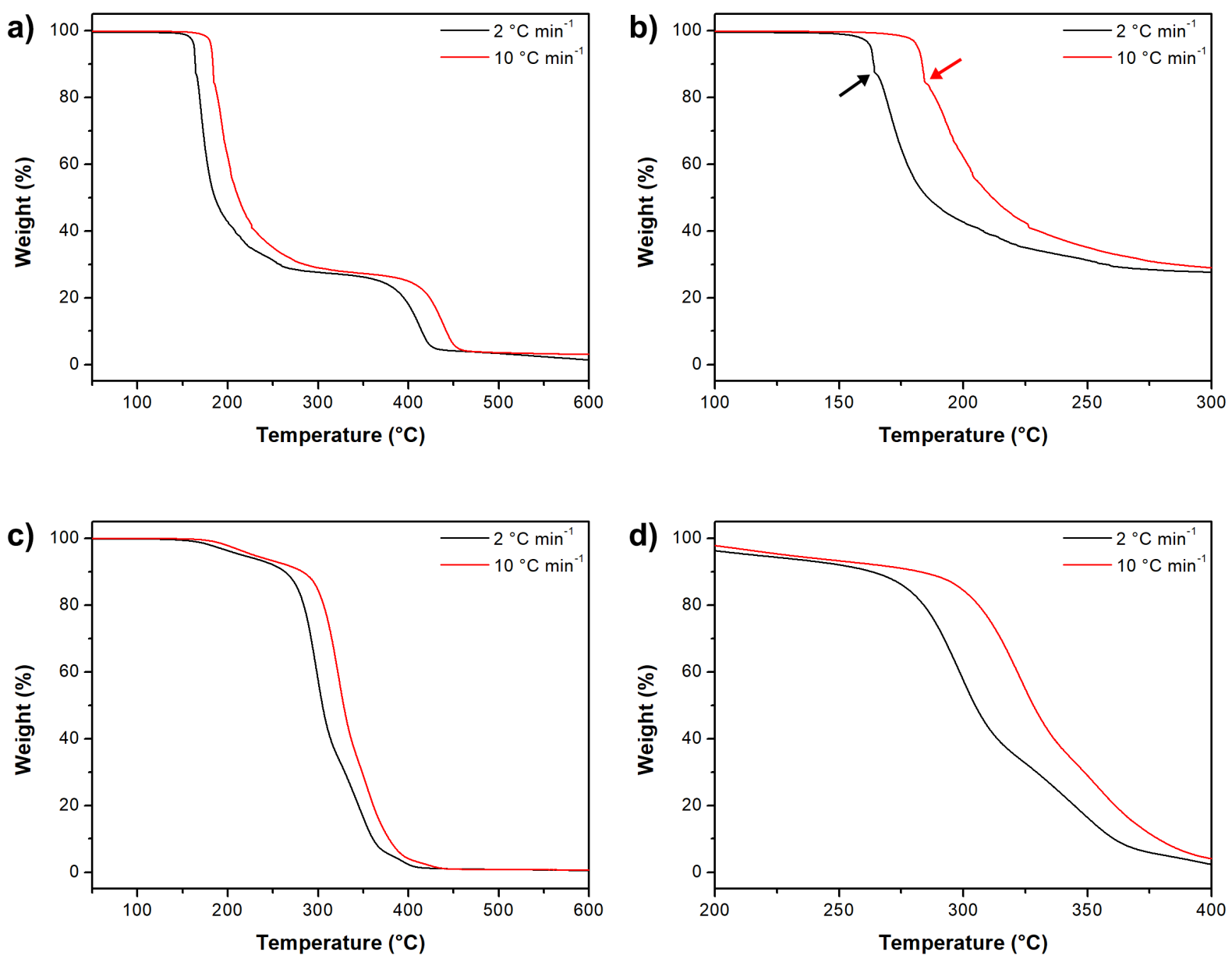

Figure S8: TGA measurements performed at 2 and $10{ }^{\circ} \mathrm{C} \mathrm{min}^{-1}$ : (a,b) PBSPMA and (c,d) PPhSPMA. No additional degradation mechanisms can be identified; profiles are only shifted. Arrows in (b) indicate the loss of PBSPMA's isobutyl protecting group $(\sim 20 \%)$. 
a)

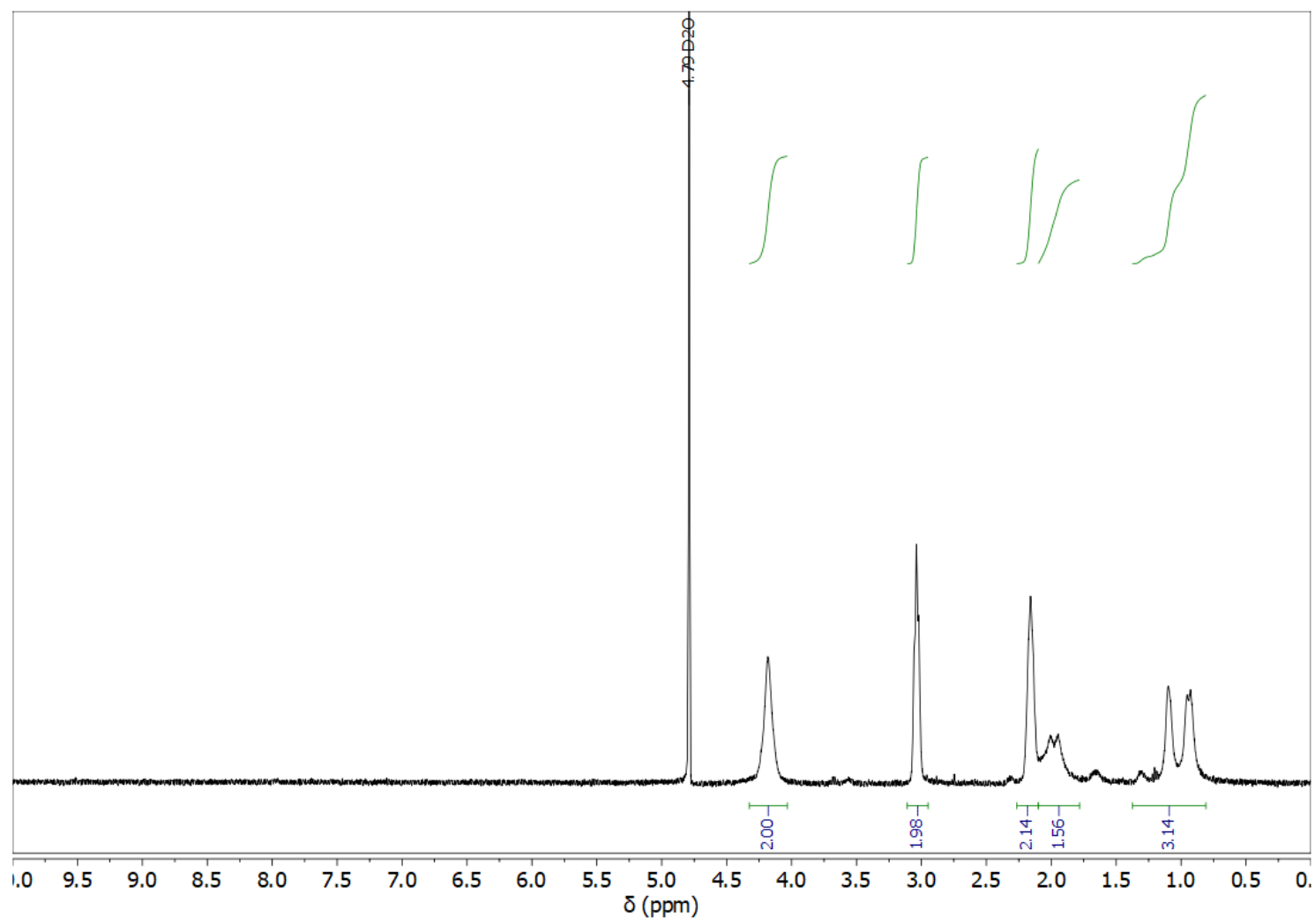

b)

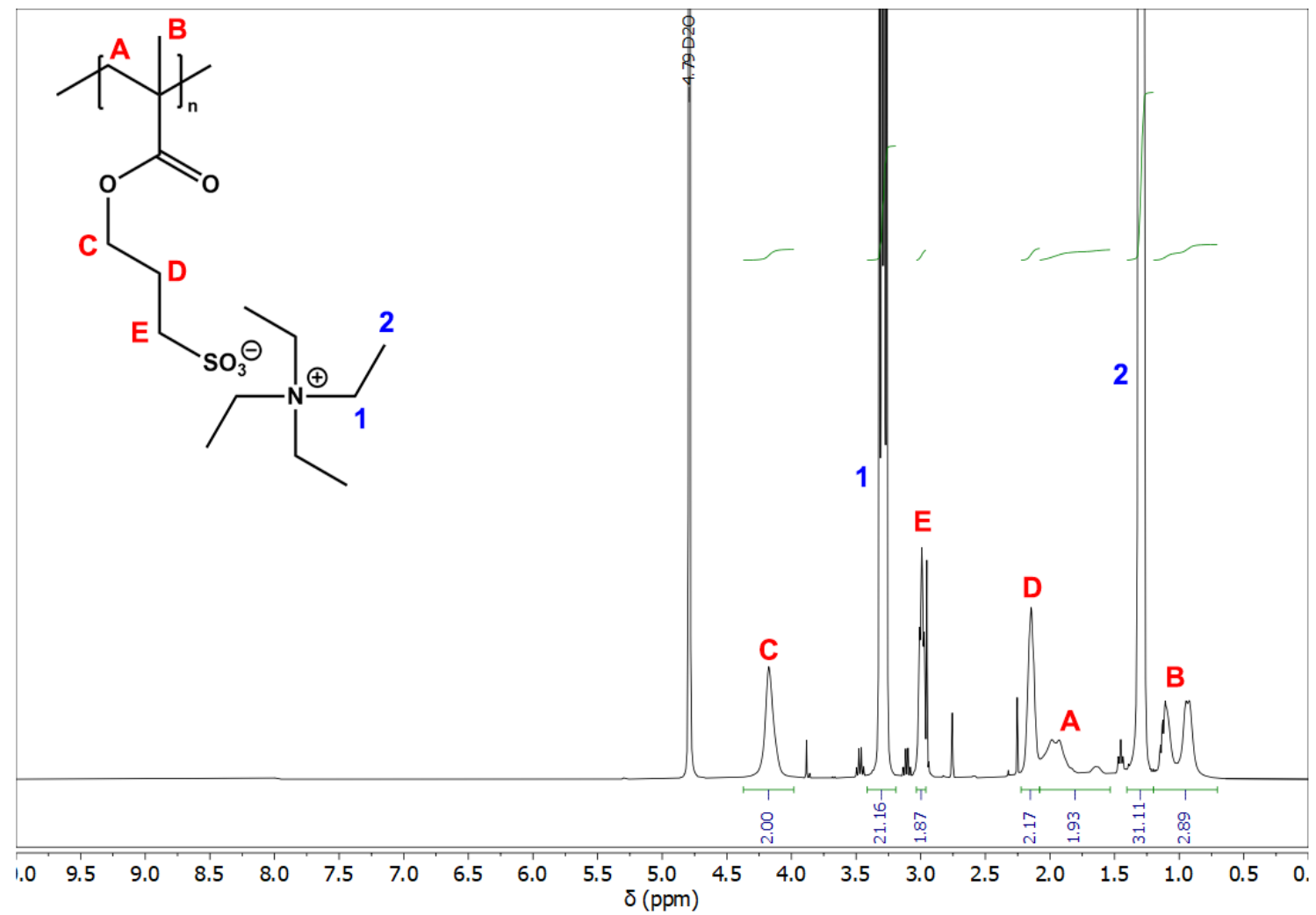

Figure S9: ${ }^{1} \mathrm{H}-\mathrm{NMR}$ spectra $\left(\mathrm{D}_{2} \mathrm{O}\right)$ of PBSPMA deprotected by (a) KI (obtained as pink powder), and (b) $\mathrm{Et}_{4} \mathrm{NI}$. In case of $\mathrm{Et}_{4} \mathrm{NI}$, the reaction mixture was precipitated into a pentane/ethanol mixture, and washed with acetone to remove any residual $\mathrm{I}_{2}$ (orange solid). Ratio PSPMA $/ \mathrm{Et}_{4} \mathrm{~N}=1 / 2.6$; the excess $\mathrm{Et}_{4} \mathrm{NI}$ may be removed by dialysis. 
a)

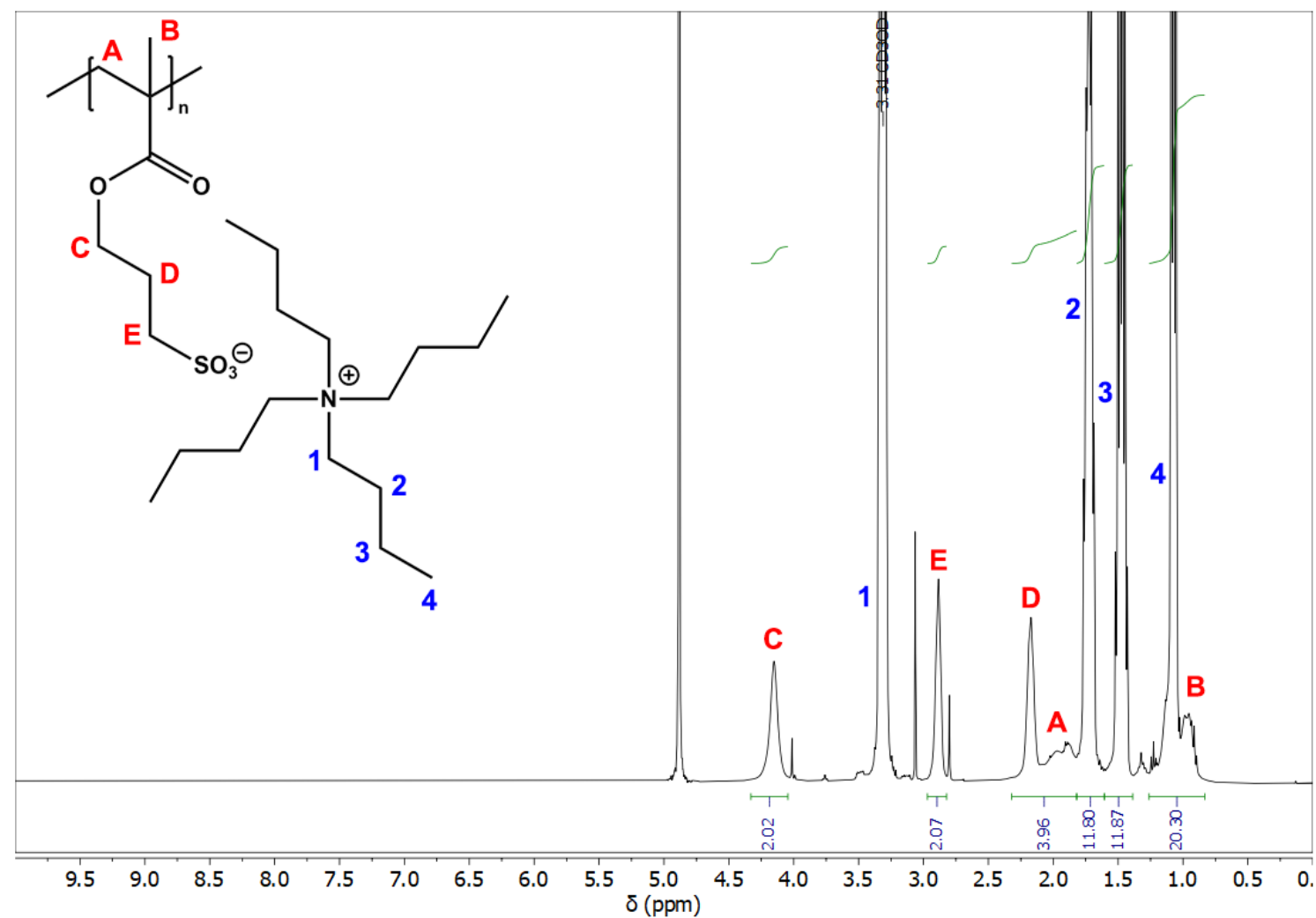

b)

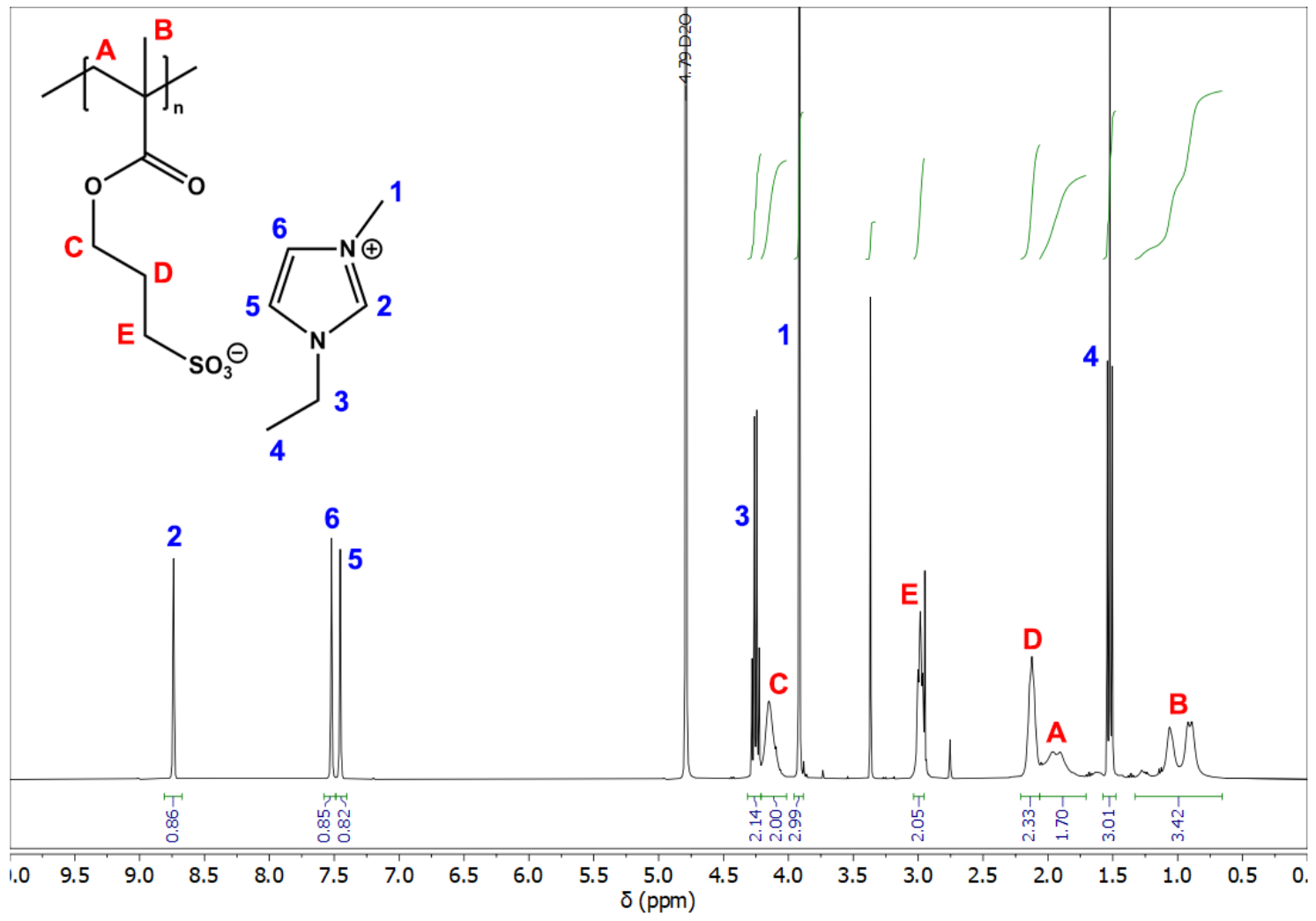

Figure S10: ${ }^{1} \mathrm{H}-\mathrm{NMR}$ spectra of PBSPMA deprotected by (a) Bu ${ }_{4} \mathrm{NI}$ (methanol- $\mathrm{d}_{4}$ ) and (b) EMIMI $\left(\mathrm{D}_{2} \mathrm{O}\right)$. $\mathrm{Bu}_{4} \mathrm{NI}$ work-up: DMSO was removed by distillation, redissolved in acetone, and precipitated into diethyl ether. The product was washed with warm THF, and dried in vacuo to obtain the product as a yellow foam. Ratio PSPMA $/ \mathrm{Bu}_{4} \mathrm{~N}=1 / 1.5$. The remaining $\mathrm{Bu} \mathrm{NI}_{4}$ may be removed by additional washing with THF or through dialysis. EMIMI work-up: DMSO was removed by distillation. The residue was washed with acetone, and dried in vacuo to obtain the product as a soft, sticky orange solid. Ratio PSPMA/EMIMI $=1 / 1$. 


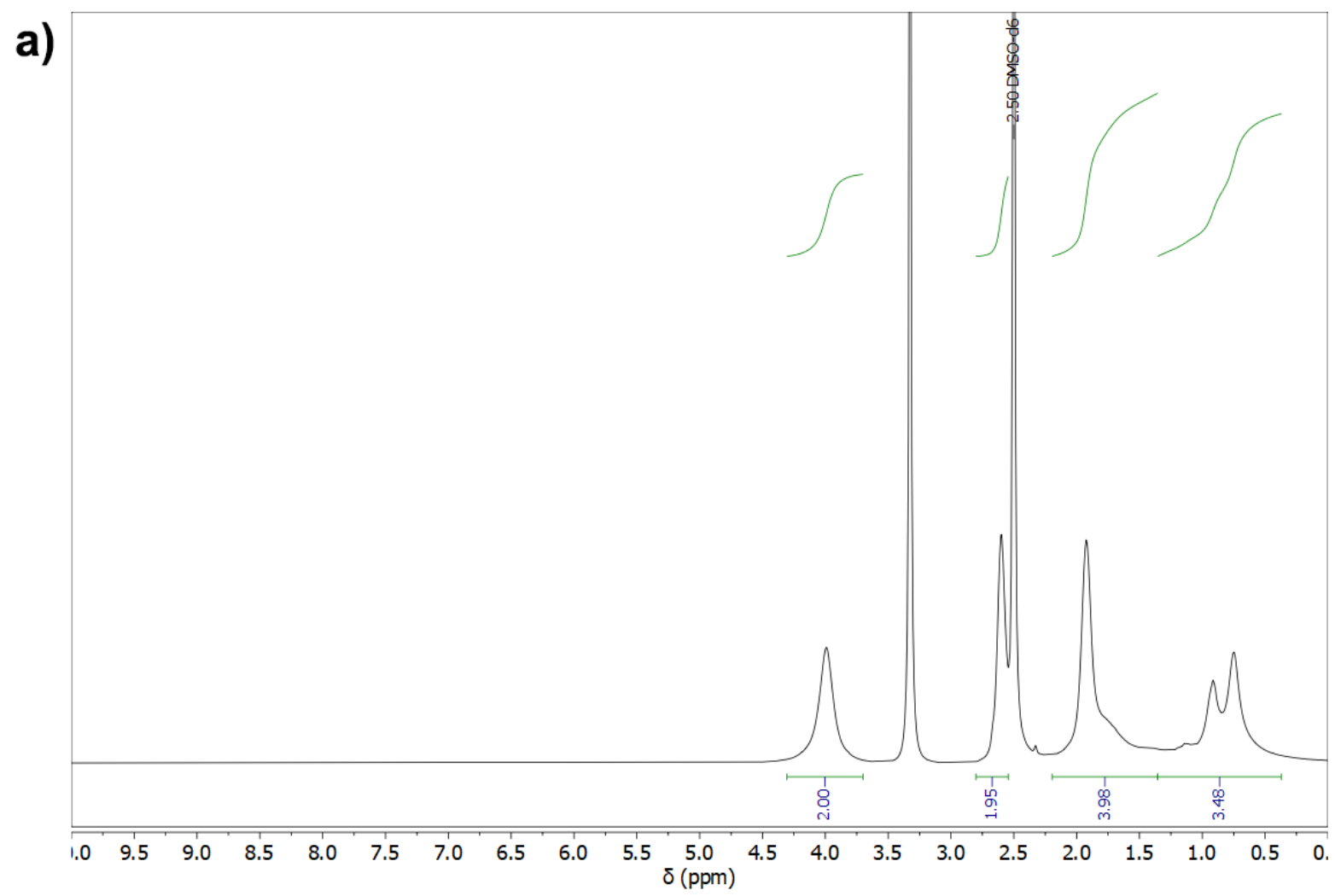

b)

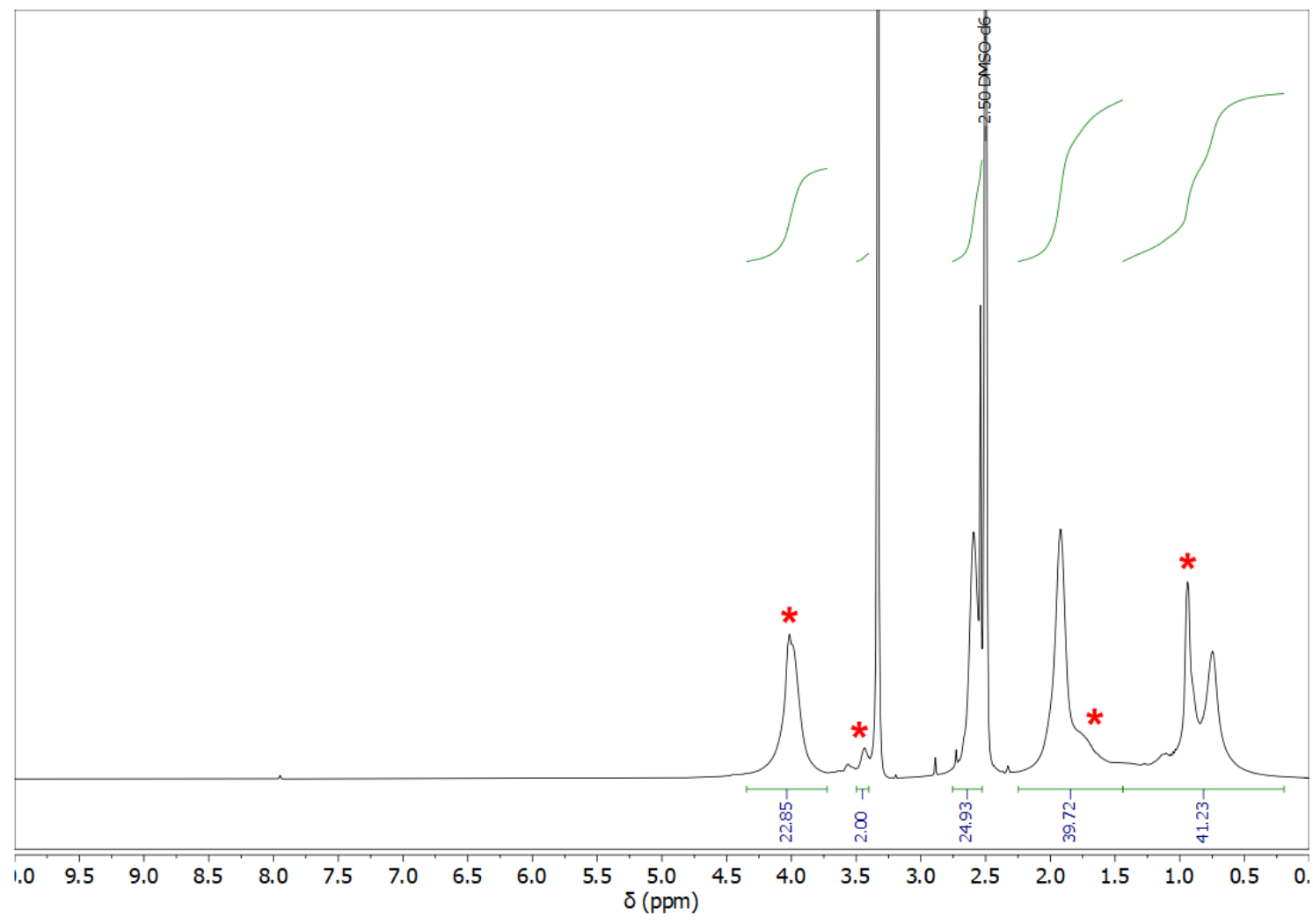

Figure S11: ${ }^{1} \mathrm{H}-\mathrm{NMR}$ spectra $\left(\mathrm{DMSO}_{-} \mathrm{d}_{6}\right)$ of PBSPMA deprotected by (a) $\mathrm{NaN}_{3}$ and (b) $\mathrm{NaOH} . \mathrm{NaN}_{3}$-treatment resulted in quantitative deprotection. Base-treatment gave $90 \%$ cleavage of the isobutyl groups $(*)$. 


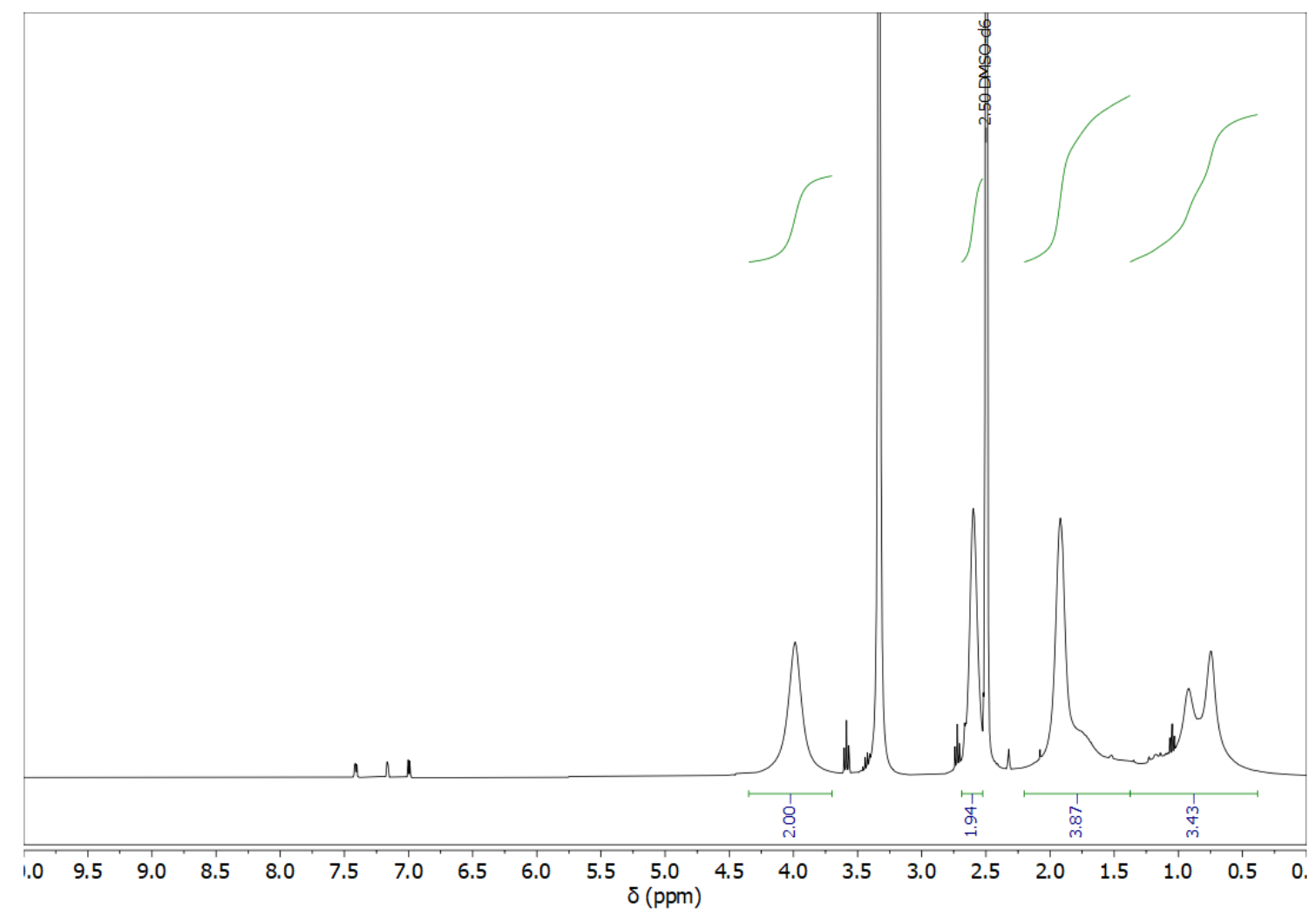

Figure S12: ${ }^{1} \mathrm{H}-\mathrm{NMR}$ spectrum $\left(\mathrm{DMSO}-\mathrm{d}_{6}\right)$ of PBSPMA treated with $\mathrm{HBr}$ : quantitative deprotection was achieved. 
a)

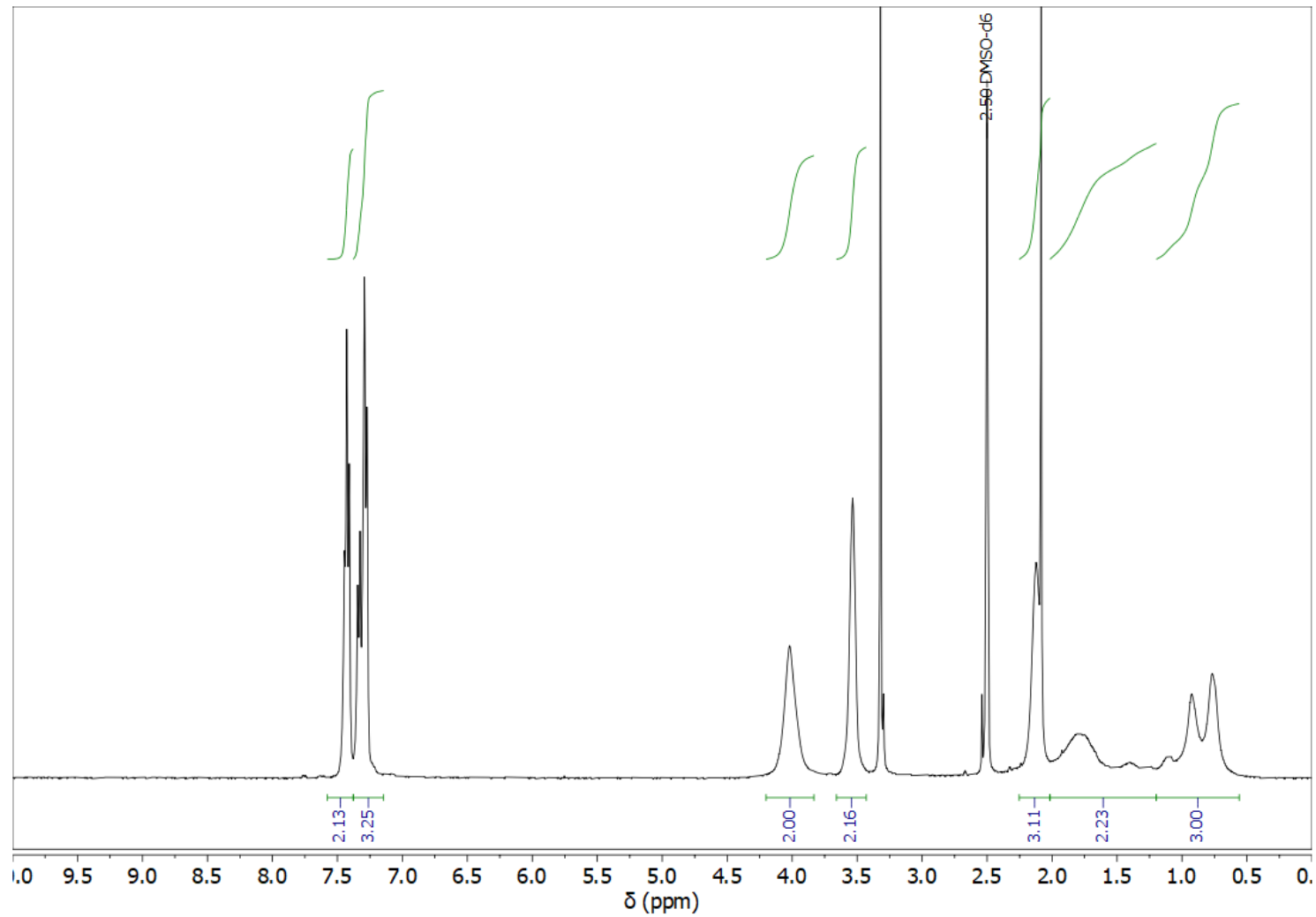

b)

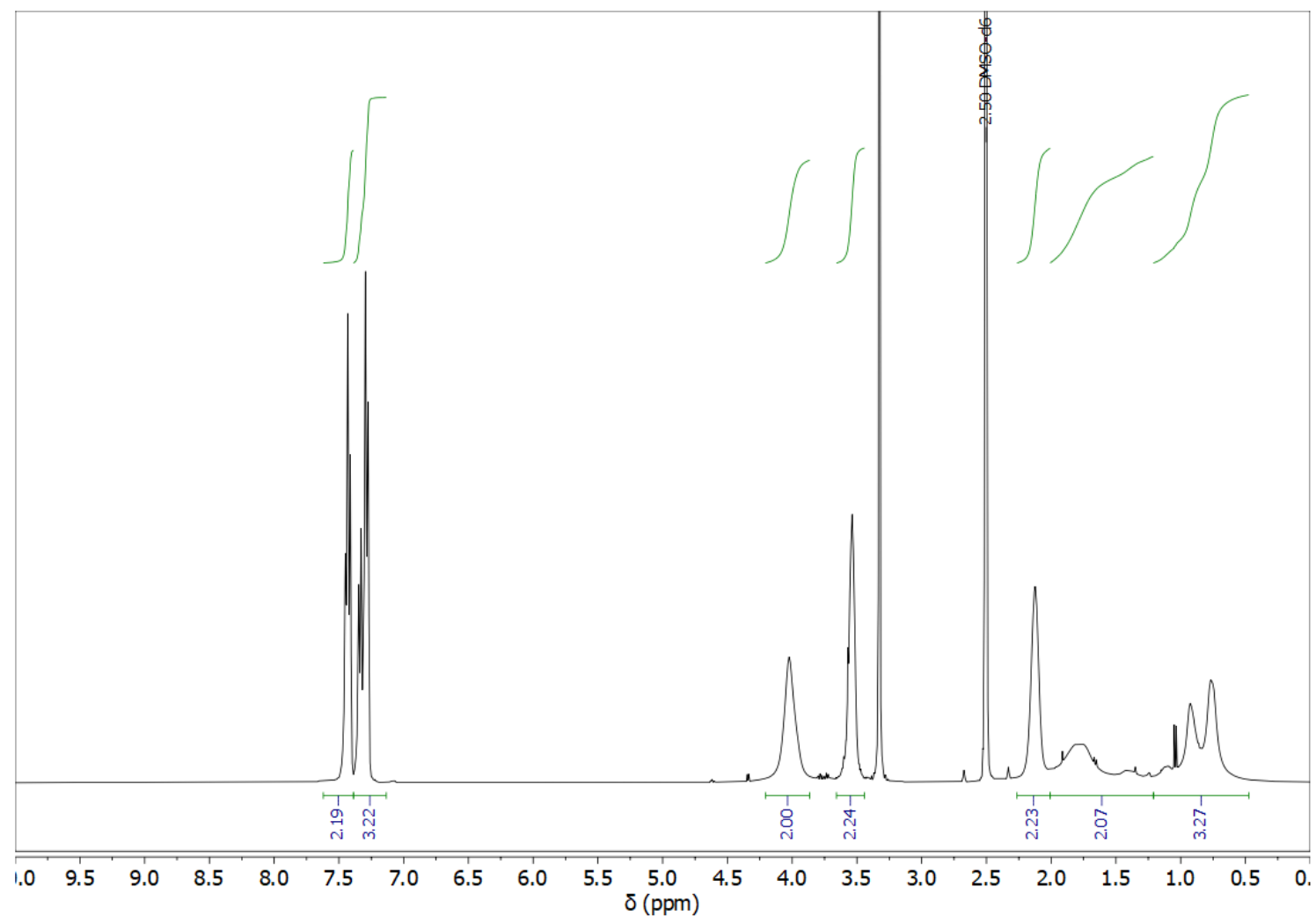

Figure S13: ${ }^{1} \mathrm{H}-\mathrm{NMR}$ spectra $\left(\mathrm{DMSO}_{-} \mathrm{d}_{6}\right)$ of PPhSPMA treated with (a) NaI and (b) $\mathrm{HBr}$. PPhSPMA remained intact in both cases. 


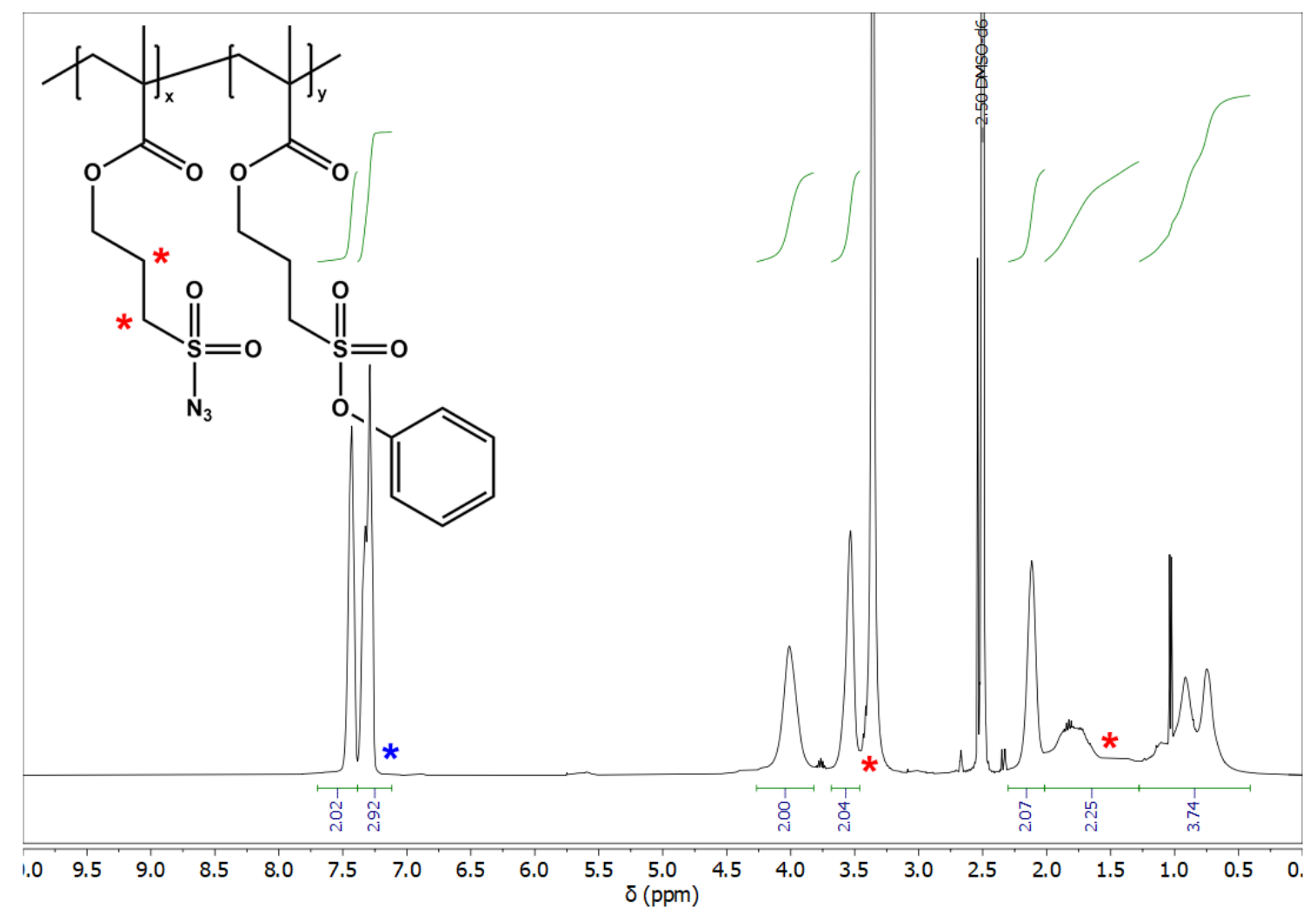

Figure S14: ${ }^{1} \mathrm{H}-\mathrm{NMR}$ spectrum $\left(\mathrm{DMSO}_{-} \mathrm{d}_{6}\right)$ of PPhSPMA after treatment with $\mathrm{NaN}_{3}$. Most protecting groups remained intact, although some phenyl groups were substituted by an azide group $(*)$. Their contribution is estimated to be approximately $10 \%$.
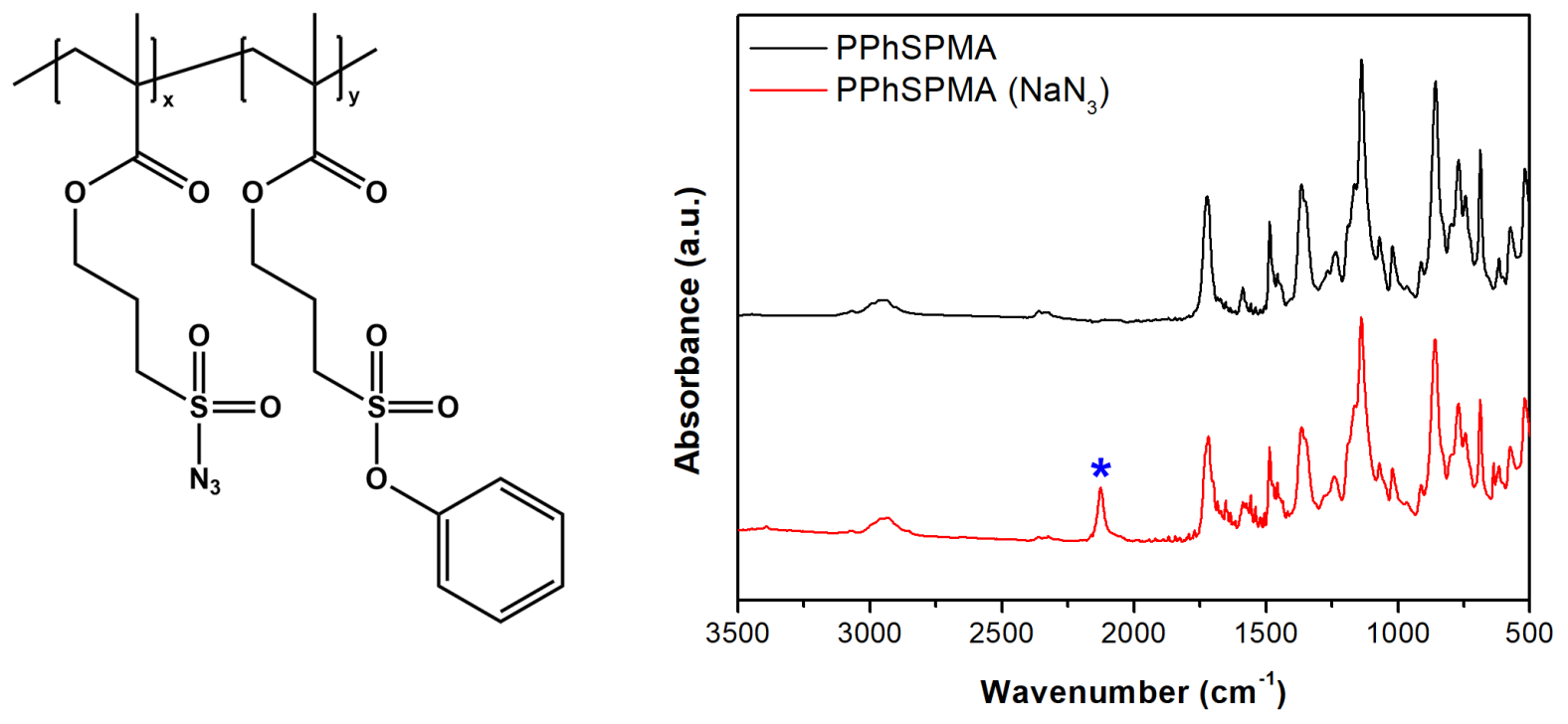

Figure S15: FTIR spectrum of PPhSPMA after $\mathrm{NaN}_{3}$-treatment. The band at $2127 \mathrm{~cm}^{-1}\left(^{*}\right)$ confirms the presence of a small number of sulfonyl azide groups. 
a)

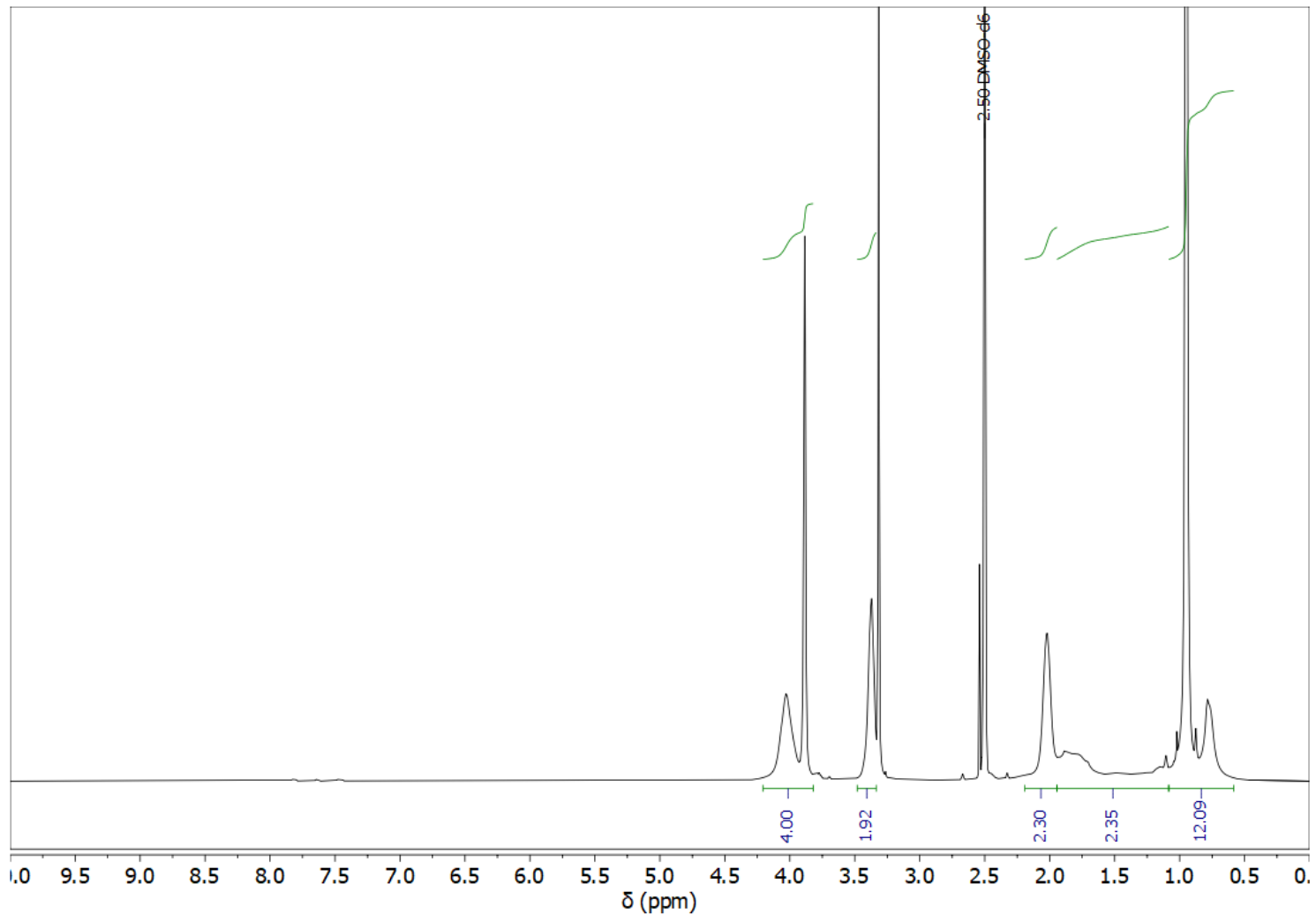

b)

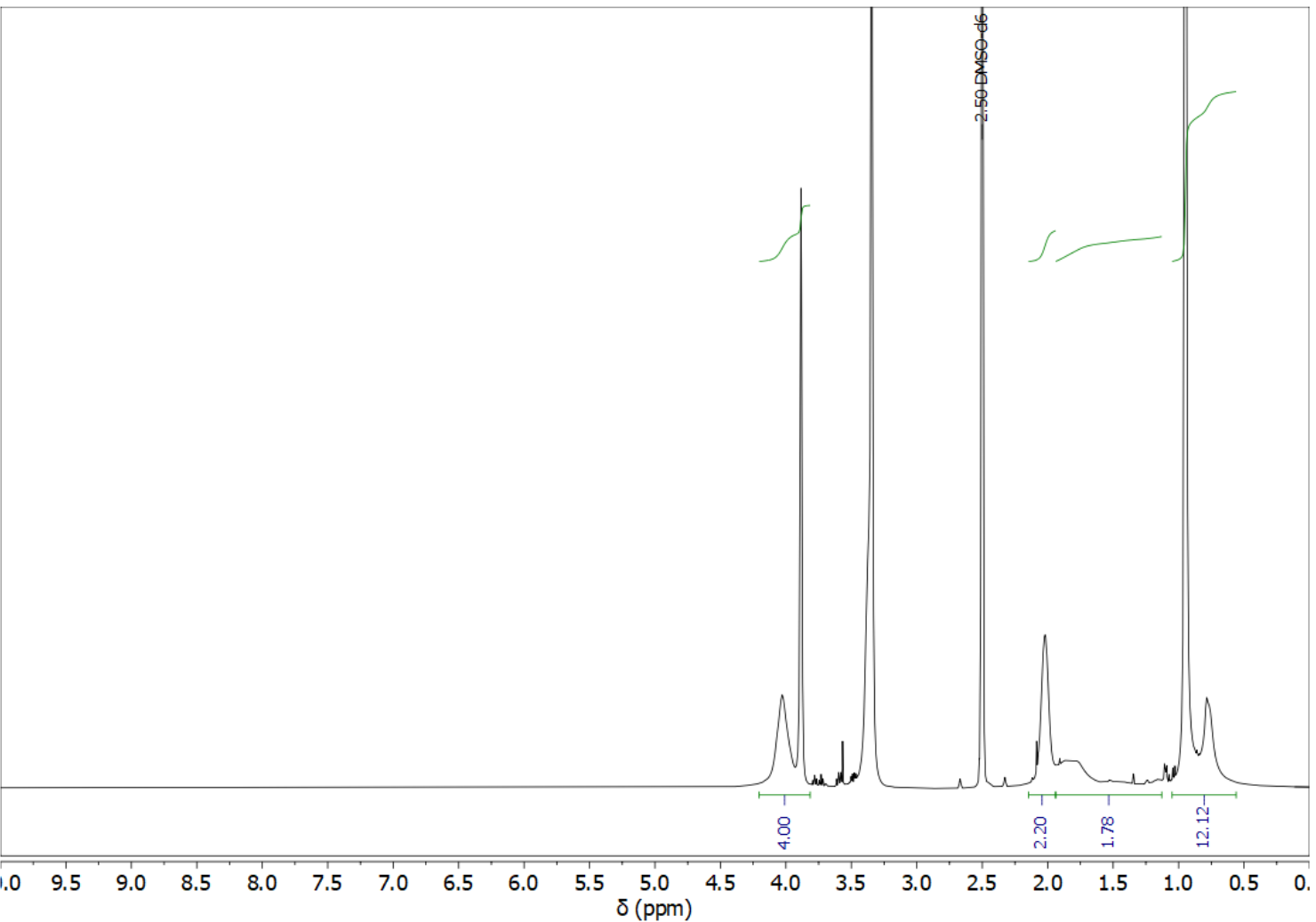

Figure S16: ${ }^{1} \mathrm{H}-\mathrm{NMR}$ spectra $\left(\mathrm{DMSO}_{\mathrm{d}}\right.$ ) of PNSPMA treated with (a) NaI and (b) HBr. PNSPMA remained unaffected by both reagents. 


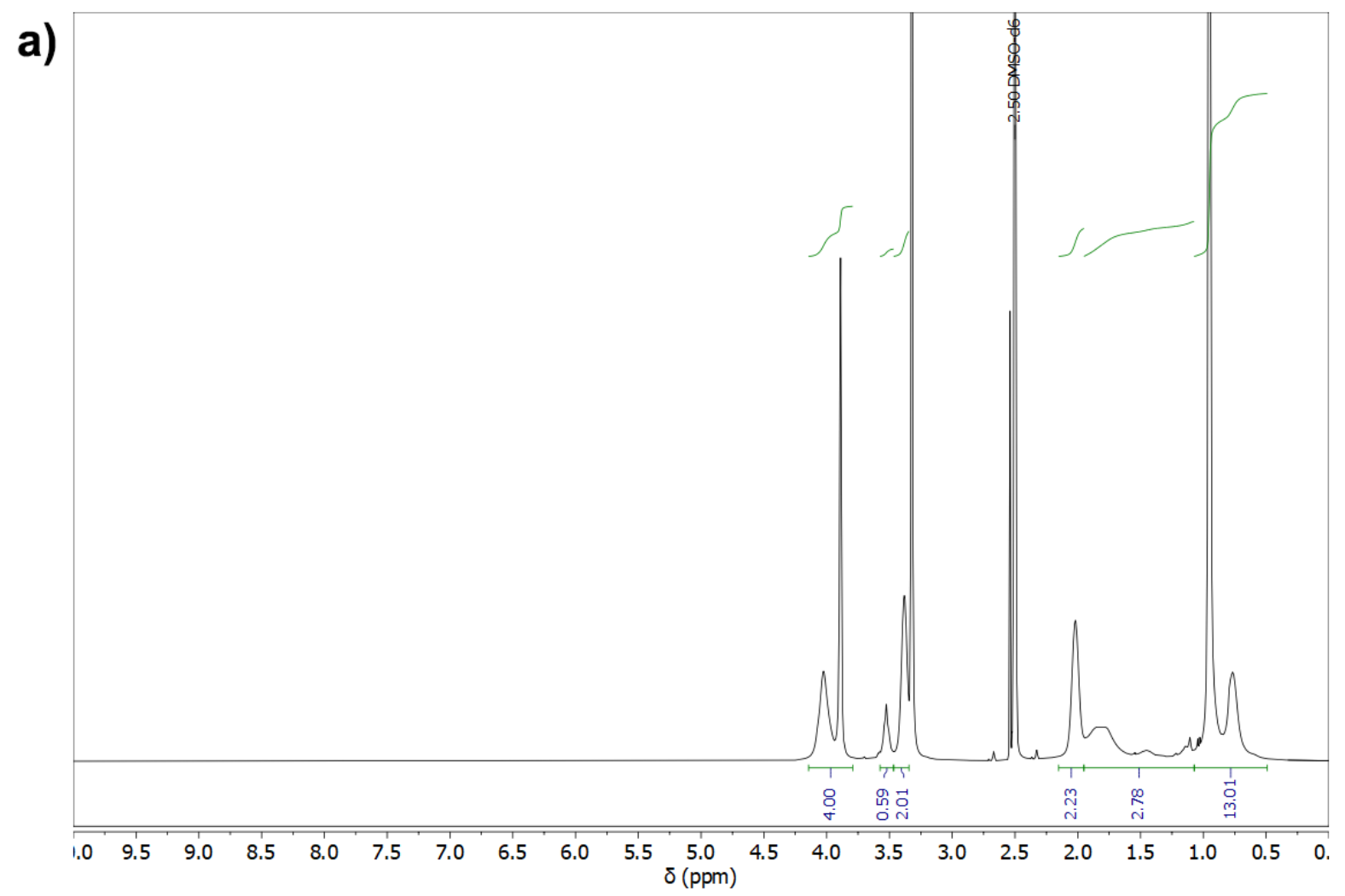

b)

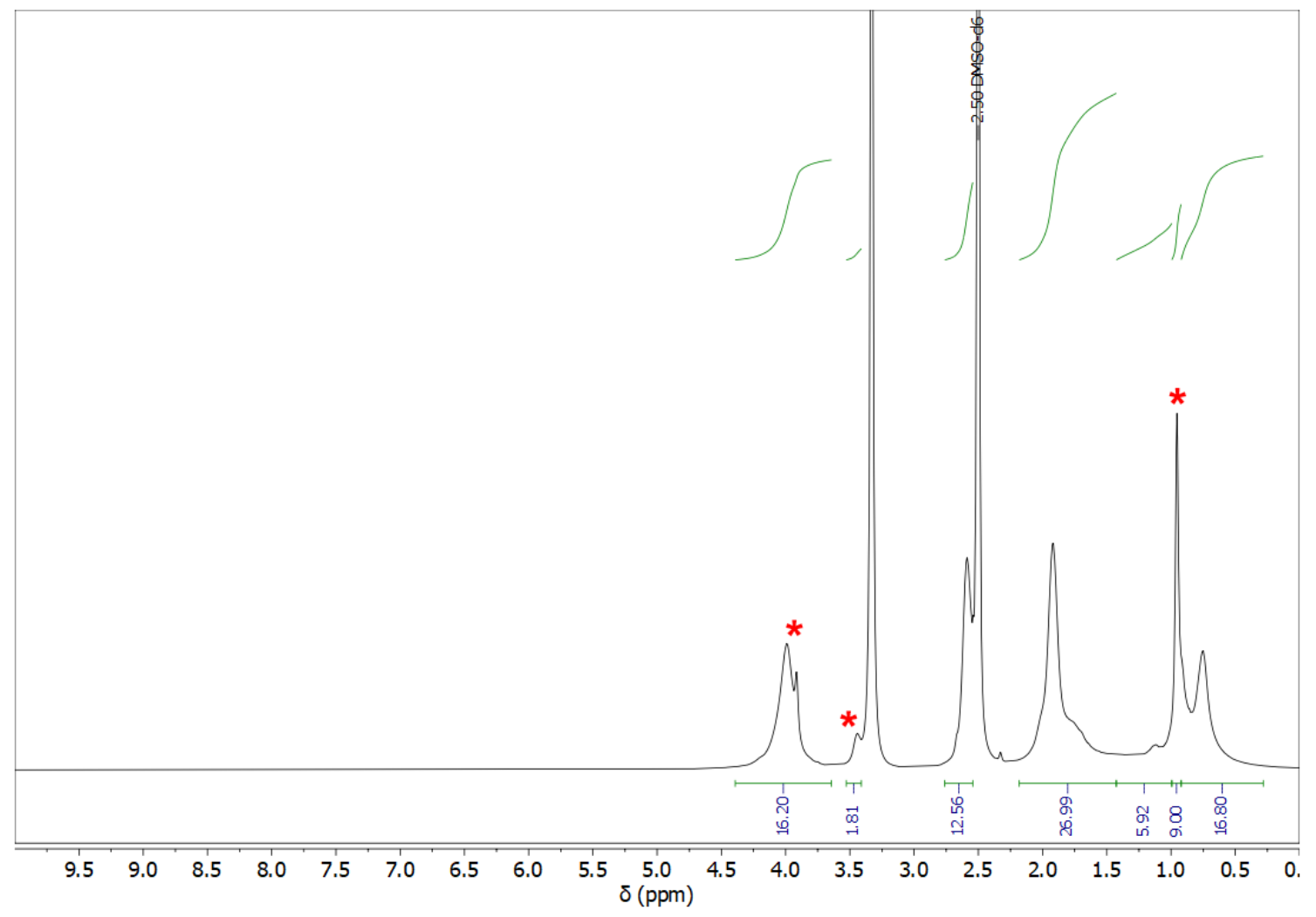

Figure S17: ${ }^{1} \mathrm{H}-\mathrm{NMR}$ spectra $\left(\mathrm{DMSO}_{\mathrm{d}}\right.$ ) of PNSPMA reacted with (a) $\mathrm{NaOH}$ and (b) $\mathrm{NaN}_{3}$ at $100{ }^{\circ} \mathrm{C}$ for 3 days. In case of $\mathrm{NaOH}$-treatment some methylation was observed $(3.5 \mathrm{ppm})$, although it did not result in deprotection of PNSPMA. $\mathrm{NaN}_{3}$ at a lower temperature gave $86 \%$ cleavage of the neopentyl groups $(*)$. 


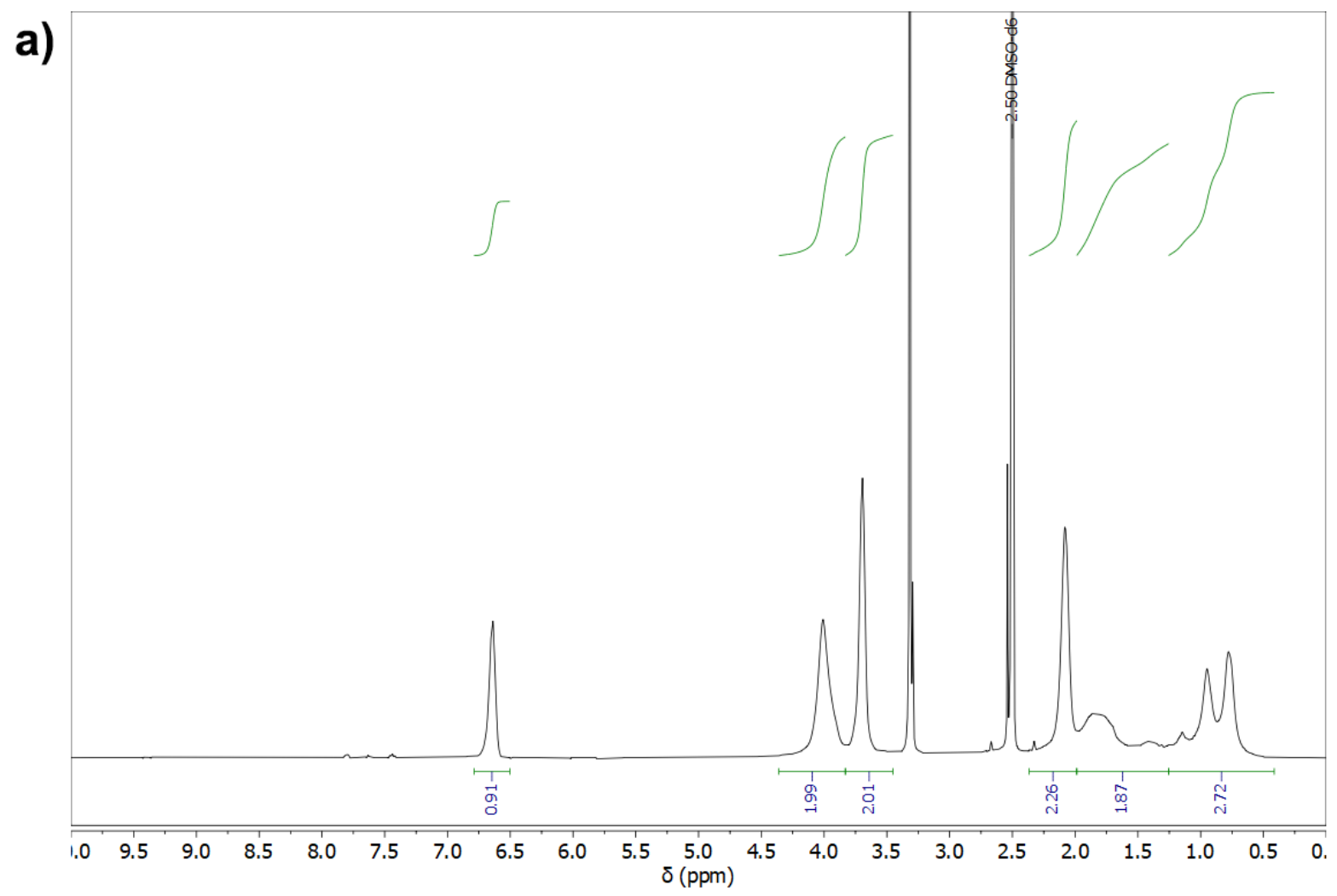

b)

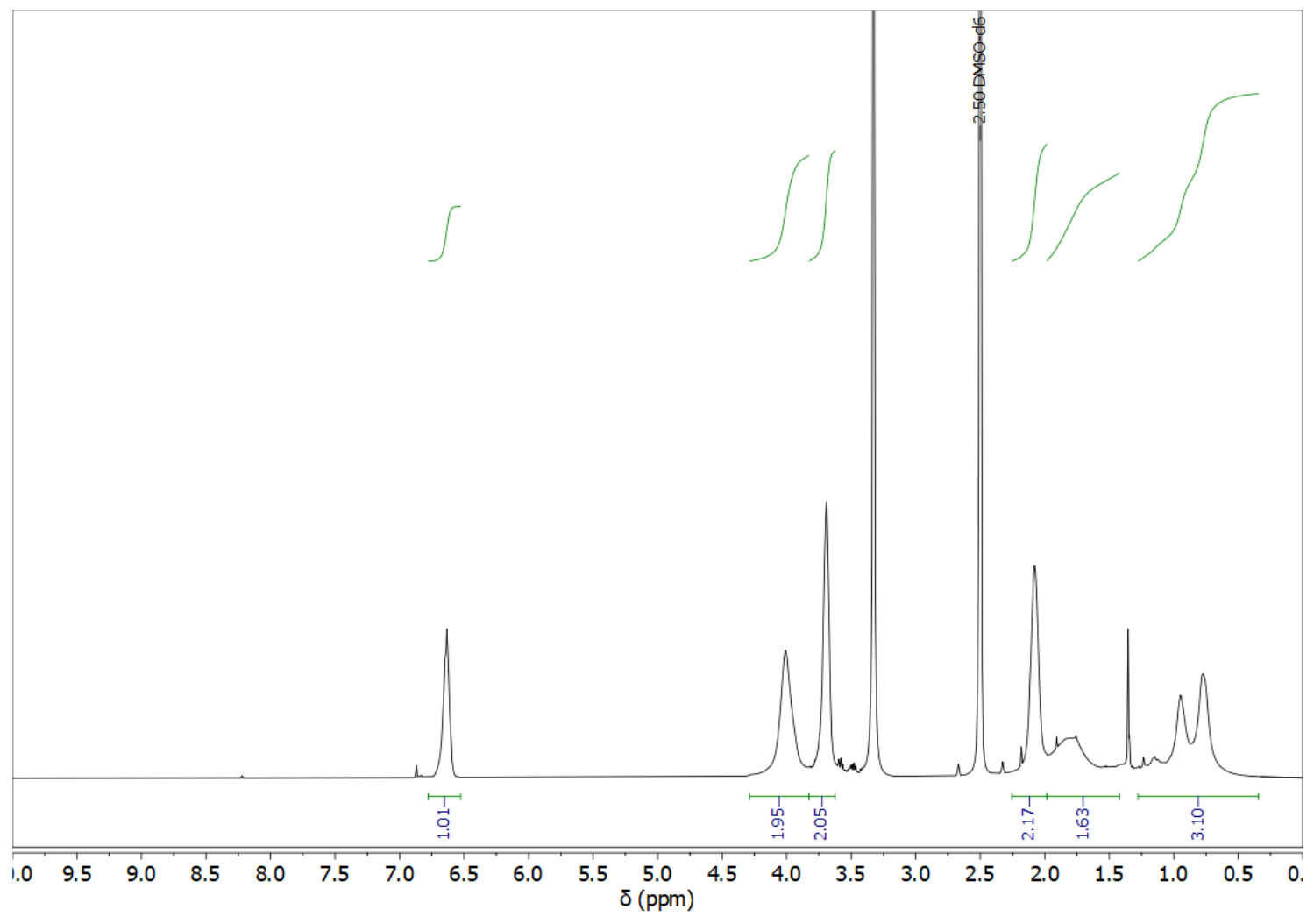

Figure S18: ${ }^{1} \mathrm{H}-\mathrm{NMR}$ spectra $\left(\mathrm{DMSO}_{-} \mathrm{d}_{6}\right.$ ) of PFSPMA treated with (a) NaI and (b) HBr. PFSPMA was not affected by both reagents. 


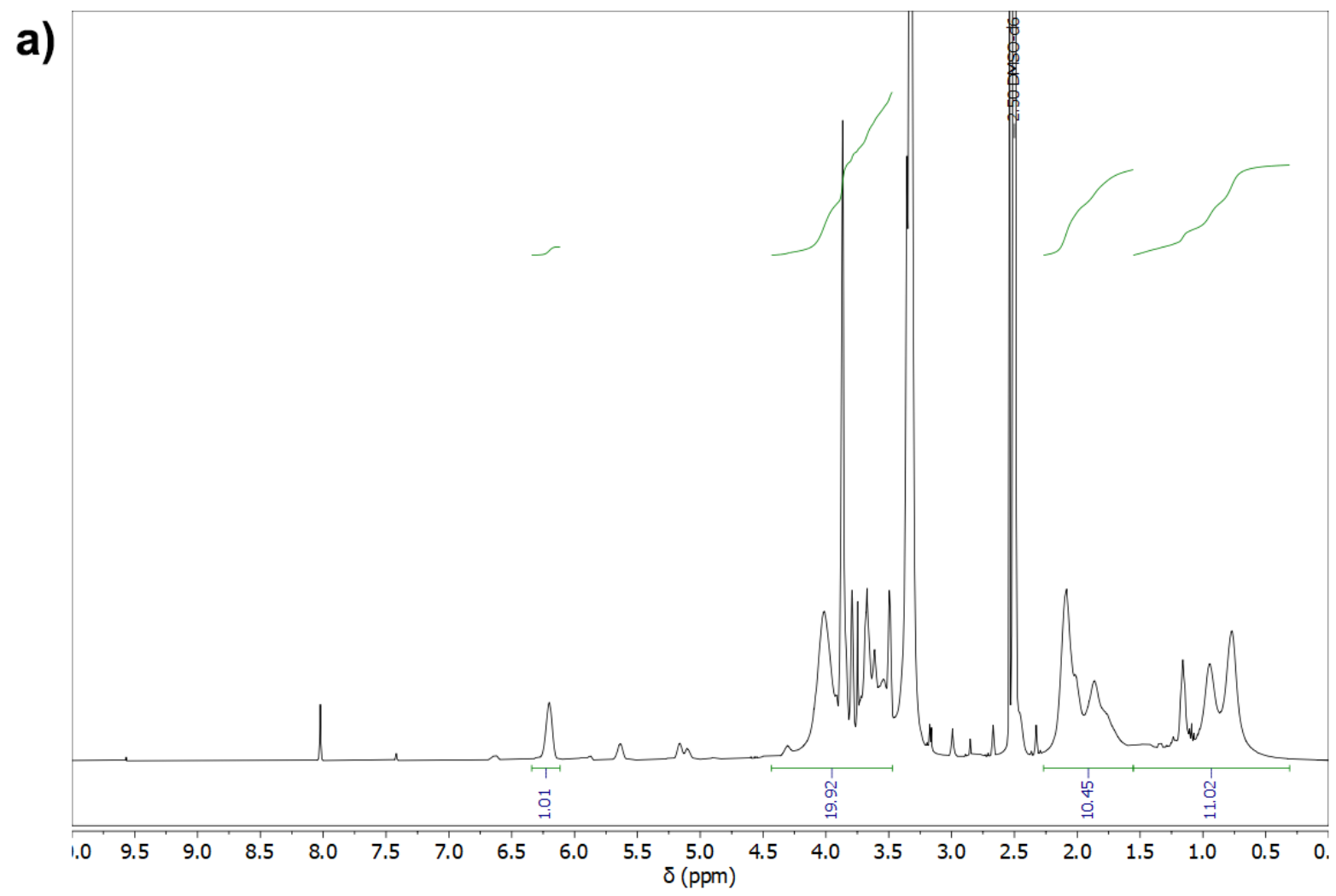

b)

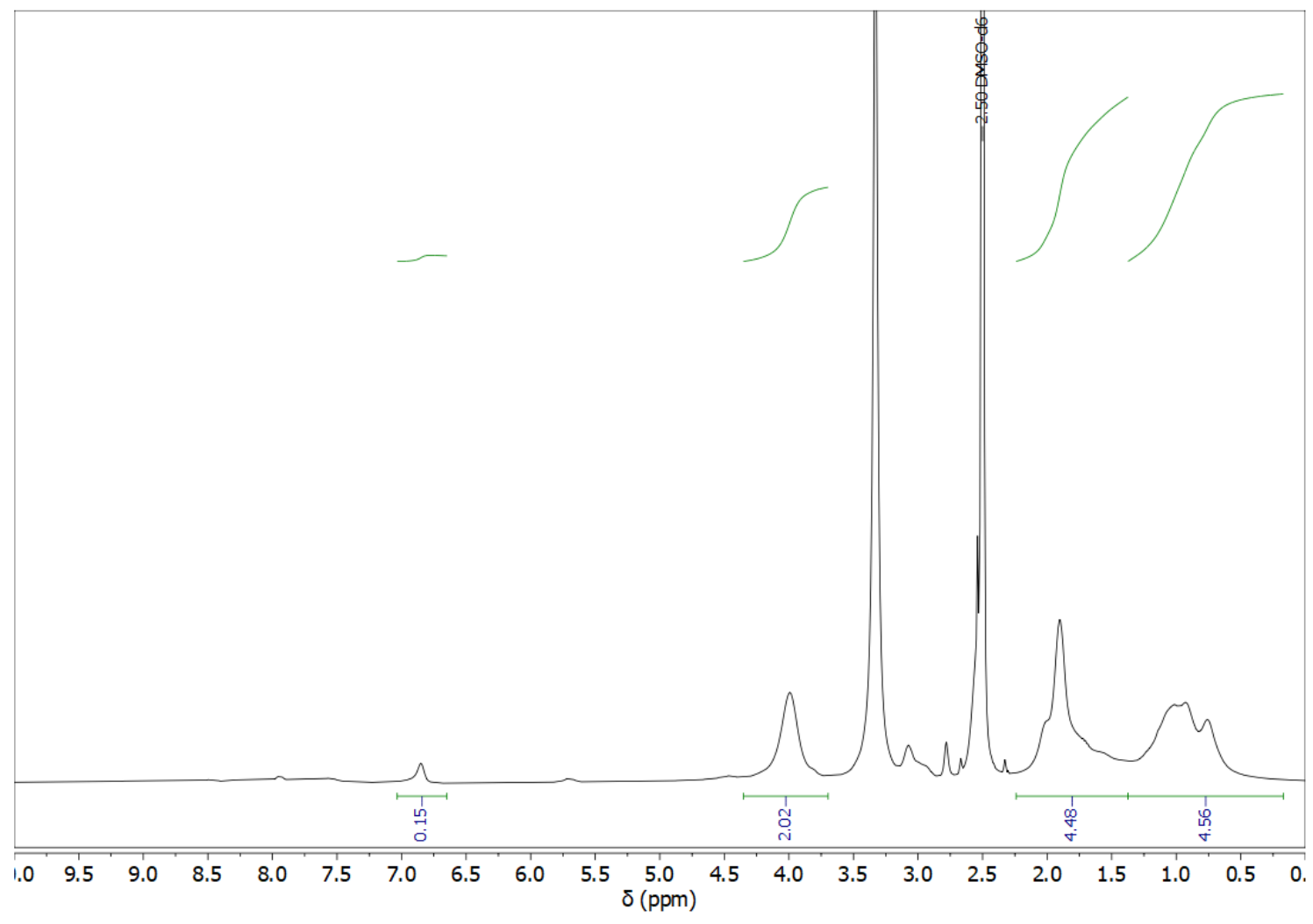

Figure S19: ${ }^{1} \mathrm{H}-\mathrm{NMR}$ spectra $\left(\mathrm{DMSO}_{6}\right.$ ) of PFSPMA reacted with (a) $\mathrm{NaOH}$ and (b) $\mathrm{NaN}_{3}$. Both conditions resulted in complex, non-informative spectra. Side reactions may include methylation $\left(\mathrm{NaOH}\right.$ in methanol/DMSO), sulfonyl azide formation $\left(\mathrm{NaN}_{3}\right.$ in DMSO), or even hydrolysis of the methacrylic ester. 
a)

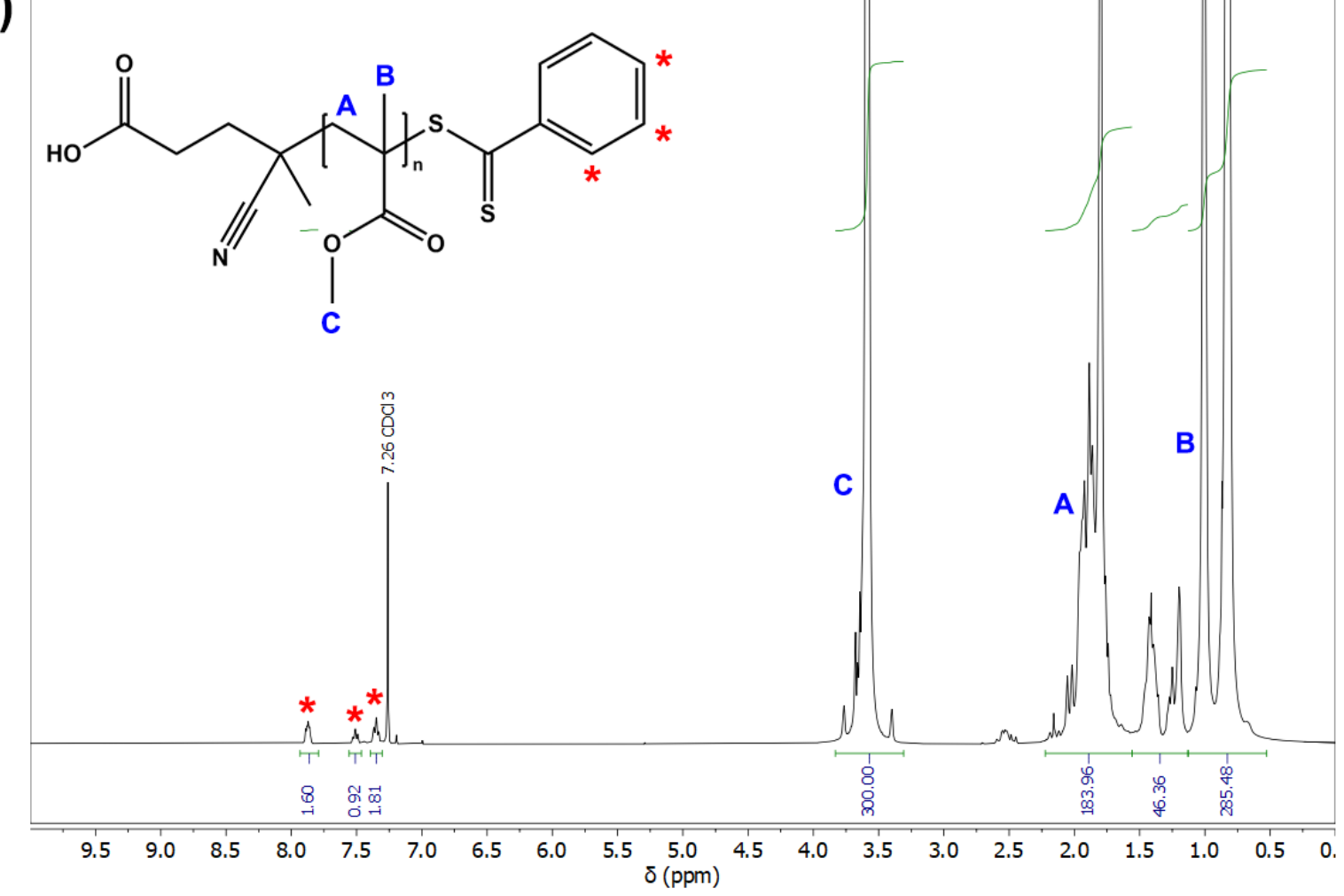

b)

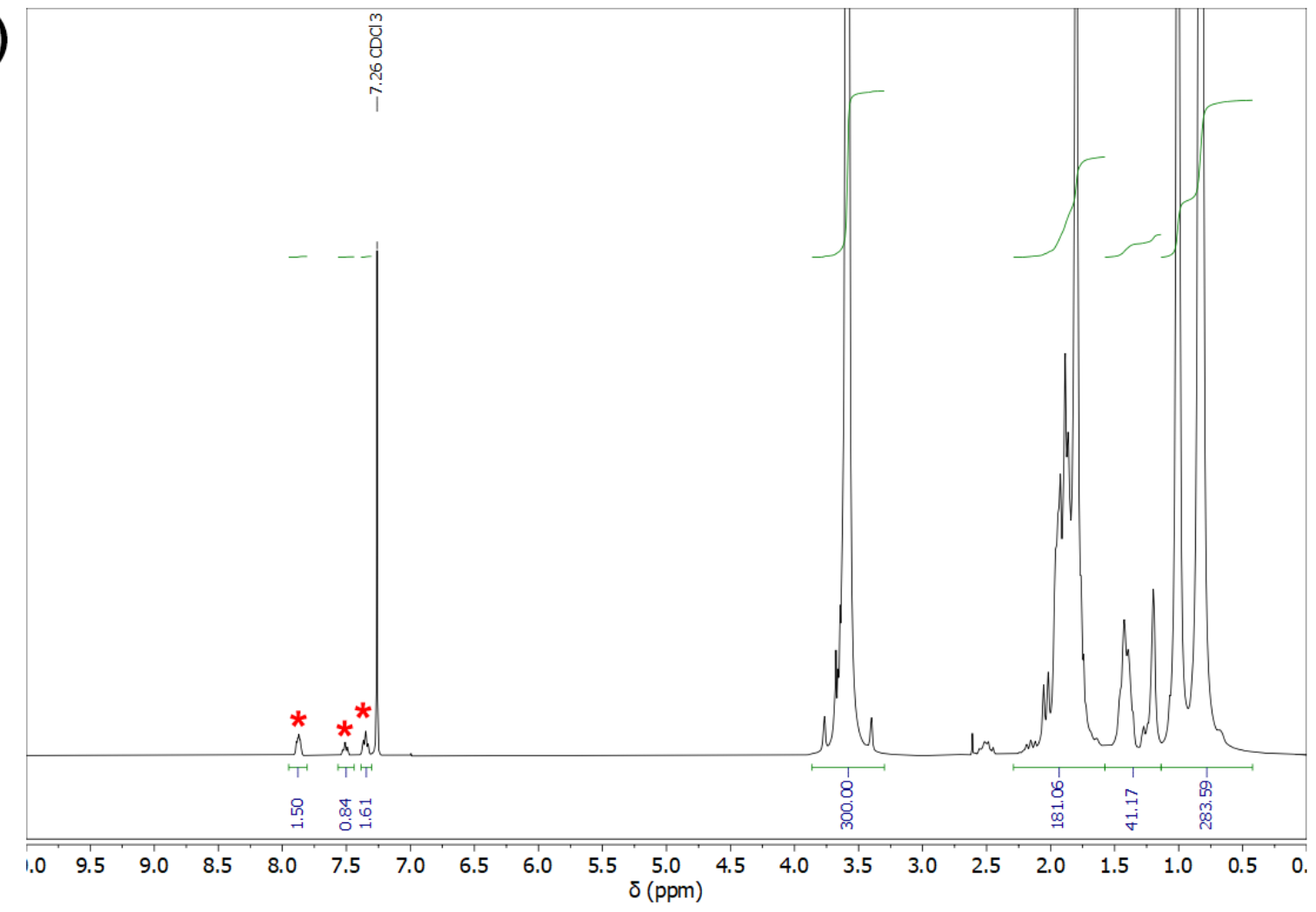

Figure S20: ${ }^{1} \mathrm{H}-\mathrm{NMR}$ spectra $\left(\mathrm{CDCl}_{3}\right)$ of PMMA $\left(M_{n}=8.63 \mathrm{~kg} \mathrm{~mol}^{-1}, Ð=1.14\right)$ recorded (a) before, and (b) after reacting with NaI. The CTA was not affected by this reagent $\left(^{*}\right)$. 


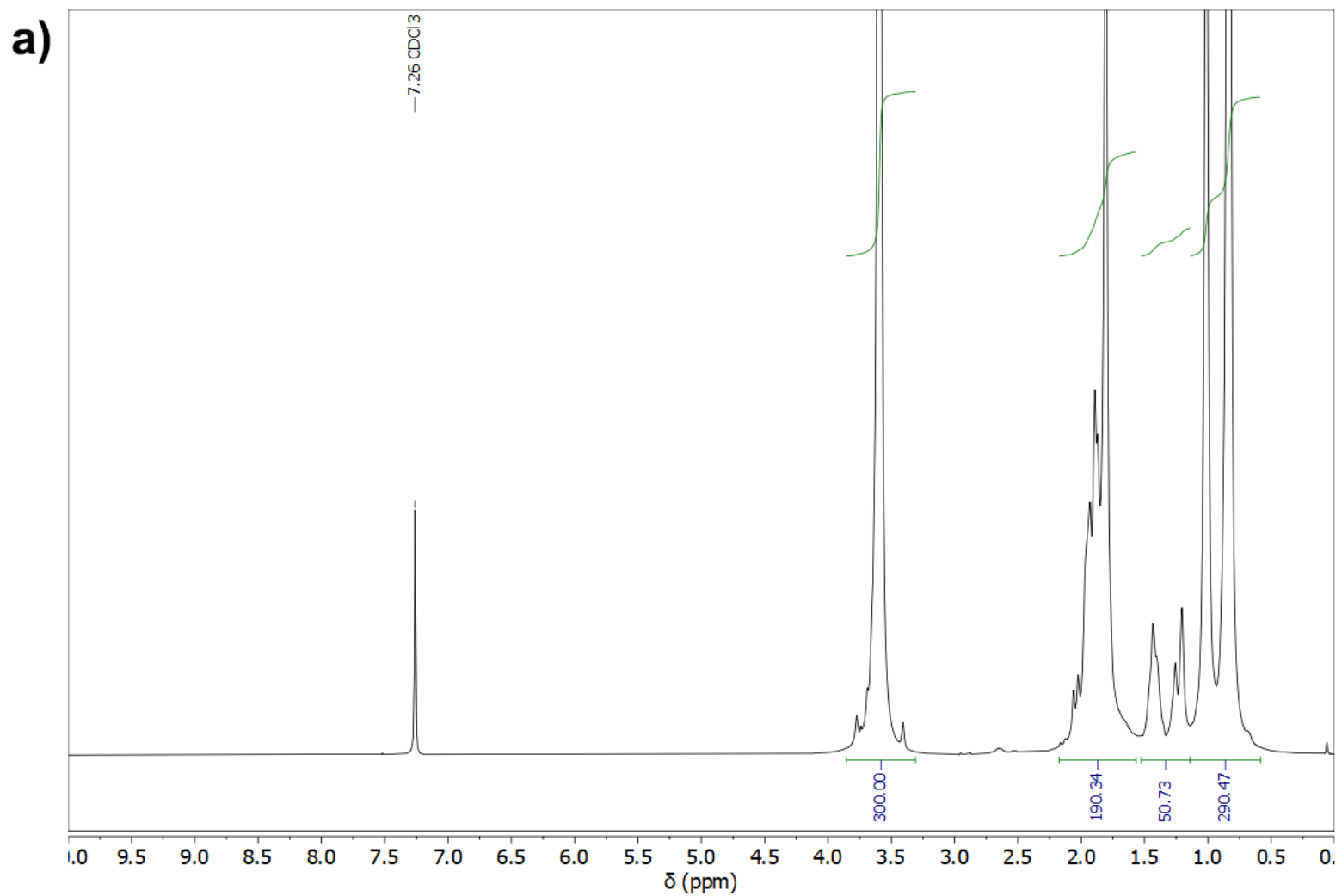

b)

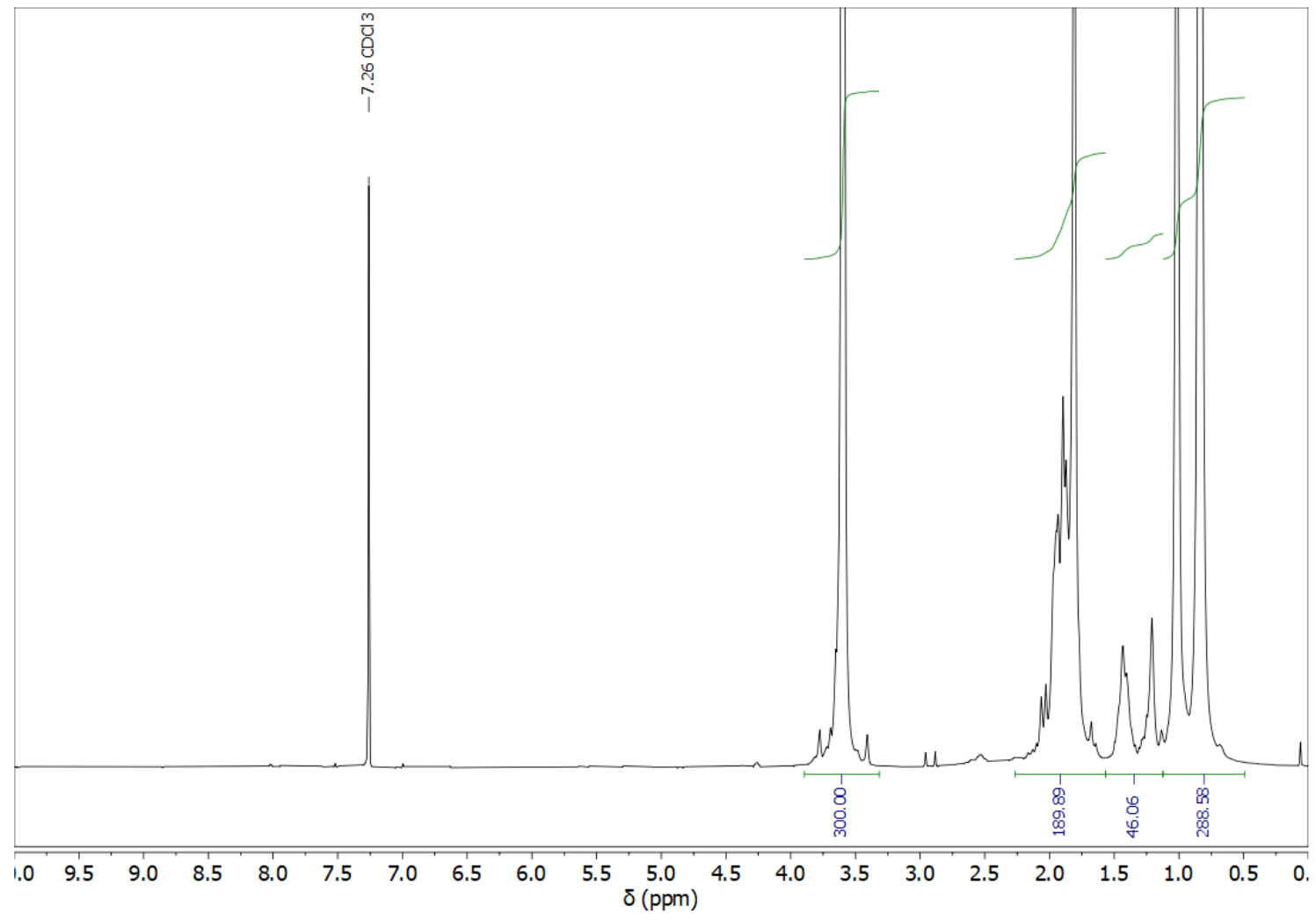

Figure S21: ${ }^{1} \mathrm{H}-\mathrm{NMR}$ spectra $\left(\mathrm{CDCl}_{3}\right)$ of PMMA $\left(M_{n}=8.63 \mathrm{~kg} \mathrm{~mol}^{-1}, \mathrm{D}=1.14\right)$ recorded after treatment with (a) $\mathrm{NaOH}$, and (b) $\mathrm{HBr}$. In both cases the characteristic CTA signals vanished, implying full removal of the dithiobenzoate functionality. 


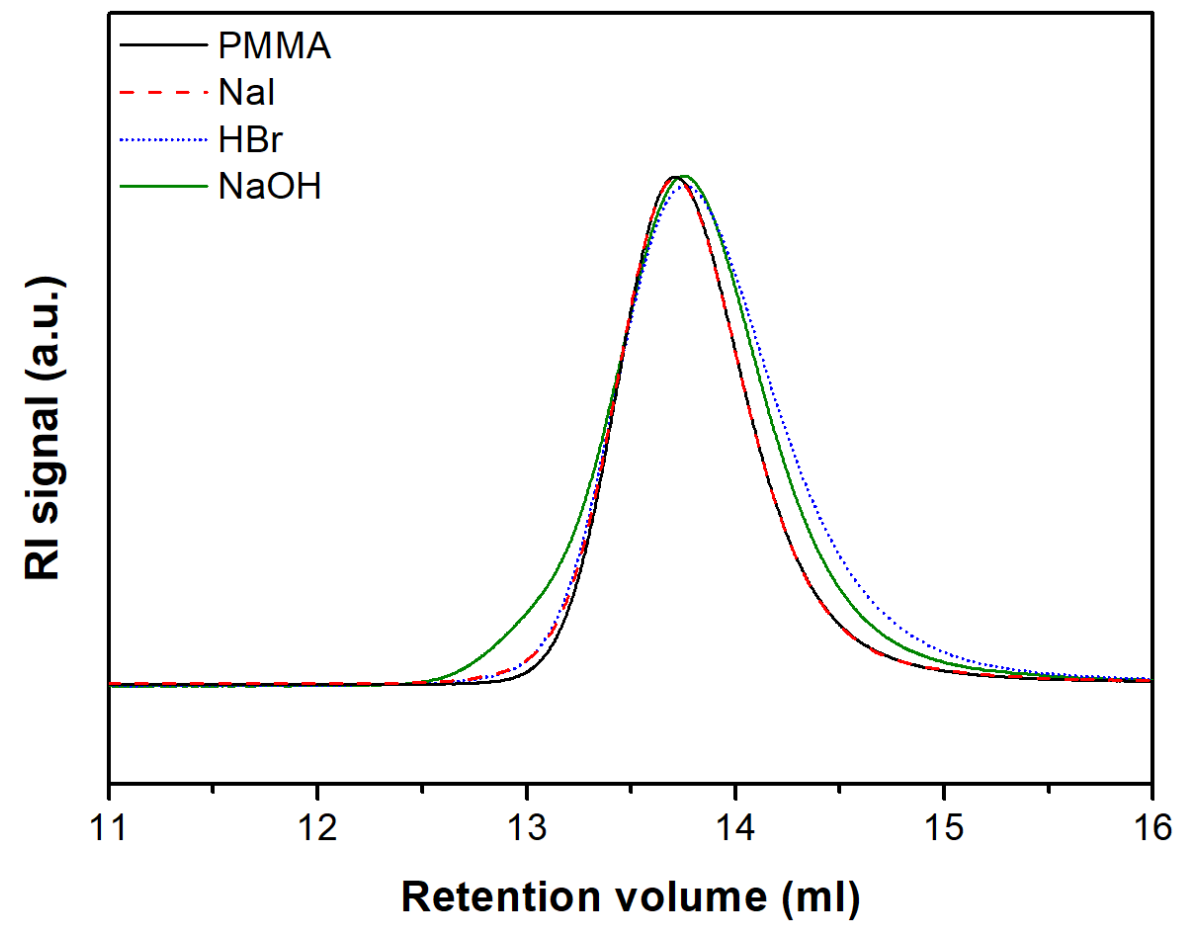

Figure S22: GPC chromatograms of PMMA $\left(M_{n}=8.63 \mathrm{~kg} \mathrm{~mol}^{-1}, \mathrm{D}=1.14\right)$ measured before and after treatment with either $\mathrm{NaI}, \mathrm{NaOH}$, or $\mathrm{HBr}$.

\begin{tabular}{|l|ccc|ccc|}
\hline \multirow{2}{*}{ Polymer } & \multicolumn{3}{|c|}{ As-prepared } & \multicolumn{3}{c|}{ Diluted } \\
\cline { 2 - 7 } & $R_{h}(\mathrm{~nm})$ & PDI & $\zeta(\mathrm{mV})$ & $R_{h}(\mathrm{~nm})$ & PDI & $\zeta(\mathrm{mV})$ \\
\hline PNeo- $b$ - $\underline{\mathrm{PPh}}$ & 55.0 & 0.184 & -35.8 & 52.1 & 0.186 & -36.4 \\
PiBu- $b$-PPh & 25.1 & 0.041 & -36.2 & 26.2 & 0.086 & -40.1 \\
PiBu- $b$-PNeo & 46.1 & 0.094 & -36.9 & 44.4 & 0.096 & -36.5 \\
\hline
\end{tabular}

Table S3: DLS data of as-prepared $\left(1.0 \mathrm{mg} \mathrm{ml}^{-1}, 11 \mathrm{mM} \mathrm{KNO}_{3}, 13 \mathrm{wt} \%\right.$ DMSO$)$ and diluted $\left(0.1 \mathrm{mg} \mathrm{ml}^{-1}, 10 \mathrm{mM} \mathrm{KNO}_{3}, 1 \mathrm{wt} \%\right.$ DMSO) anionic/hydrophobic diblock copolymer solutions. The deprotected block is underlined. 
a)

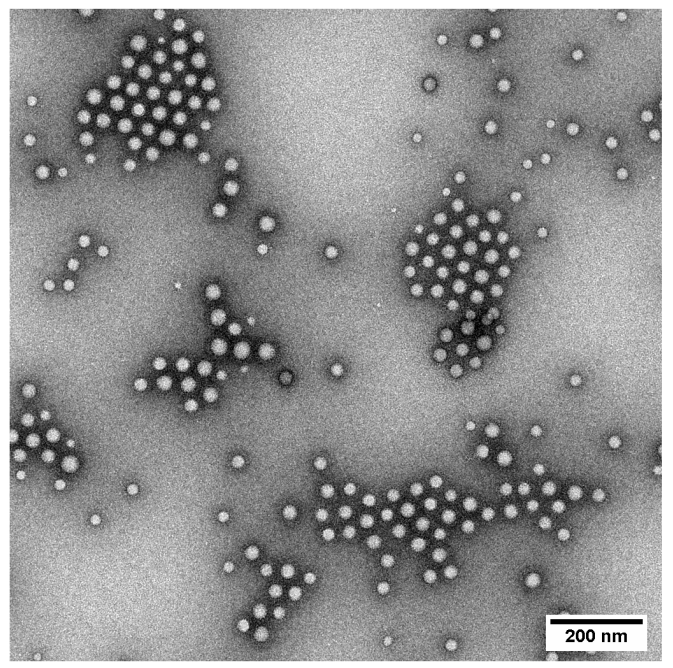

c)

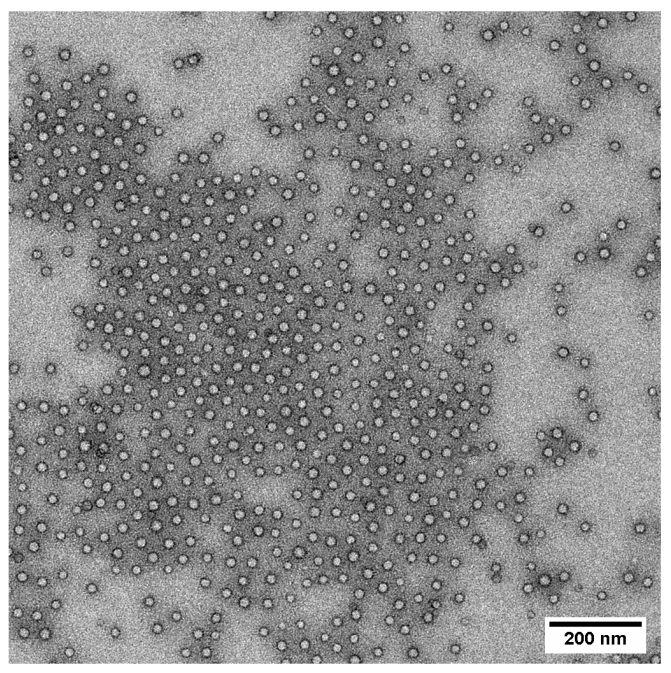

e)

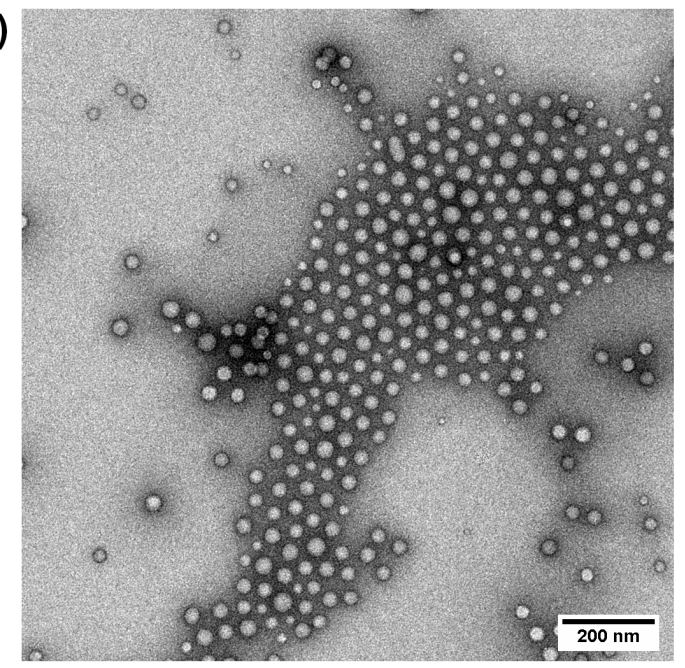

b)

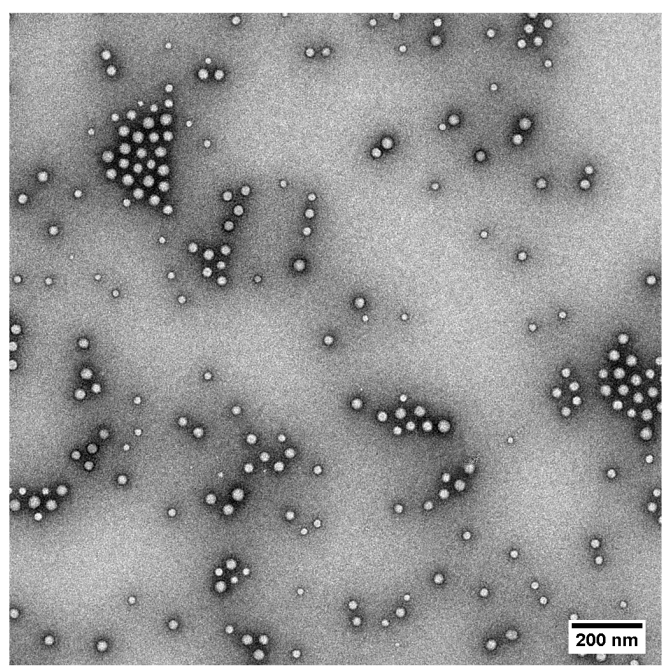

d)

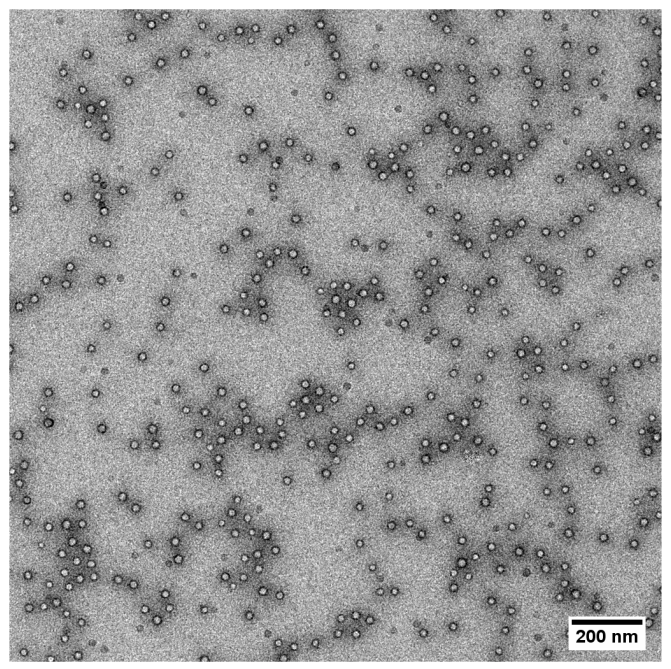

f)

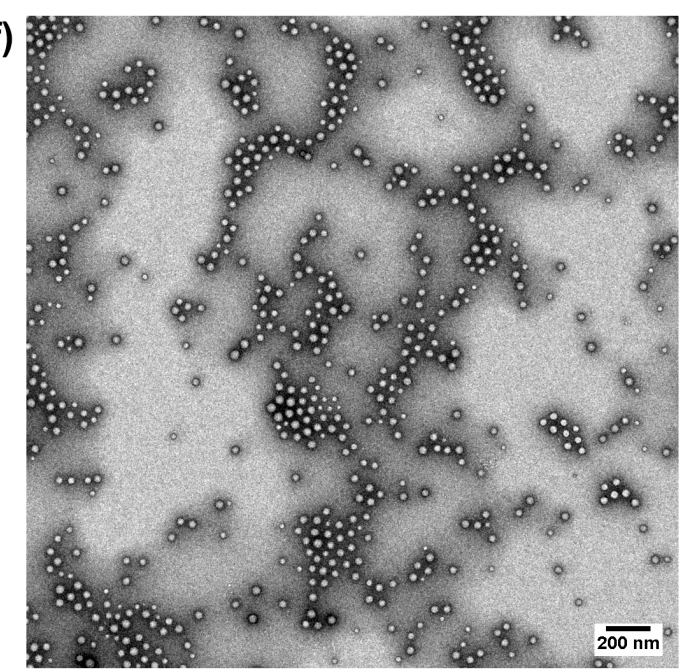

Figure S23: TEM images of negatively stained block copolymer aggregates recorded at a

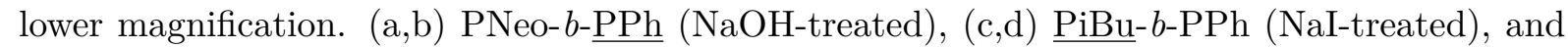
$(\mathrm{e}, \mathrm{f})$ PiBu- $b$-PNeo (NaI-treated). The deprotected block is underlined. 


\section{References}

1. Hofman, A. H.; Fokkink, R.; Kamperman, M. A Mild and Quantitative Route Towards Well-Defined Strong Anionic/Hydrophobic Diblock Copolymers: Synthesis and Aqueous Self-Assembly. Polym. Chem. 2019, 10, 6109-6115.

2. Zhang, L.; Eisenberg, A. Thermodynamic vs Kinetic Aspects in the Formation and Morphological Transitions of Crew-Cut Aggregates Produced by Self-Assembly of Polystyrene- $b$-poly(acrylic acid) Block Copolymers in Dilute Solution. Macromolecules 1999, 32, 2239-2249.

3. Lebel, R. G.; Goring, D. A. I. Density, Viscosity, Refractive Index, and Hygroscopicity of Mixtures of Water and Dimethyl Sulfoxide. J. Chem. Eng. Data 1962, 7, 100-101.

4. Dubin, P. L.; Principi, J. M. Failure of Universal Calibration for Size Exclusion Chromatography of Rodlike Macromolecules versus Random Coils and Globular Proteins. Macromolecules 1989, 22, 1891-1896.

5. Dondos, A.; Papanagopoulos, D. Modification of the Universal Calibration of Gel Permeation Chromatography to Include Macromolecules Presenting a Draining Effect. J. Polym. Sci. Part B: Polym. Phys. 2003, 41, 707-710. 